\title{
A new mechanism for anticipating price exuberance ${ }^{\hbar}$
}

\author{
Afonso M. Moreira ${ }^{\text {a }}$, Luis F. Martins ${ }^{\text {b,c,* }}$ \\ ${ }^{\text {a }}$ Portuguese Securities Market Commission, CMVM, Lisbon, Portugal \\ ${ }^{\mathrm{b}}$ ISCTE-IUL, BRU-IUL, Portugal \\ ${ }^{\mathrm{c}}$ CIMS-University of Surrey, UK
}

\section{A R T I C L E I N F O}

JEL Classification:

C22

G17

\section{Keywords:}

Speculative bubbles

Asset pricing

Non-stationarity

Adaptive learning

Dynamic models

\begin{abstract}
A B S T R A C T
It is very important for investors, market regulators, and policy makers to possess a trustworthy exante tool capable of anticipating price exuberance events. This paper proposes a new statistical mechanism to predict speculative bubbles by inferring a significant probability of exuberance at least one step ahead of a bubble peak period. Contrary to other approaches, we combine asset pricing modeling and non-stationarity statistical analysis and use both in the context of adaptive learning to build a dynamic model specification. Monte Carlo simulations show that the ex-ante prediction is improved enormously by adding the estimated abnormal returns into the model. In some cases our mechanism predicts $100 \%$ of the last bubbles of the sample up to five periods before the peak. Furthermore, the mechanism is able to successfully anticipate the technological bubble observed in the 1990's by estimating a probability greater than $90 \%$, one month before the bubble peak. Thus, this new mechanism provides an advantage for investors interested in performing a very profitable "bubble surfing" strategy and for market regulators whose responsibility is to maintain market efficiency.
\end{abstract}

\section{Introduction}

The advent of the recent financial crisis drew attention to the systemic dangers of excessive individual risk taking. Since the first documented event of price exuberance, the "Tulipomania", 1 economists have been trying to understand how investors react in such market conditions. Modern finance theory is grounded on the concept of market efficiency as in Fama (1970), in which market price reflects all the available information, and general economic theory considers the price system as reflecting the maximization of consumers' utility. The existence of speculative bubbles constitutes an exception to the former reasoning and, by consequence, they need to be properly identified.

The price of a stock in a particular period is the infinite sum of all the expected future dividends, meaning that the stocks will be worth a certain amount of money only if the underlying fundamentals are able to generate a certain value of dividends. When price exuberance ends, one perceives a considerable gap between the observed price and the underlying fundamentals supporting that same

\footnotetext{
in We thank participants at the 69th European Meeting of the Econometric Society, the 14th Infiniti Conference on International Finance, and the 2017 World of Finance Conference for helpful comments. The Financial support of Fundação para a Ciência e a Tecnologia under the Strategic Project UID/GES/00315/2019 is gratefully acknowledged. The usual disclaimer applies.

* Corresponding author.

E-mail addresses: afonsomoreira.moreira95@gmail.com (A.M. Moreira), luis.martins@iscte-iul.pt (L.F. Martins).

1 This speculative event happened in Holland in 1637 and was characterized by the preposterous increase in the price of tulip bulbs, in which the most collectible bulbs reached prices equivalent of luxury real estate.
} 
price, bursting the speculative bubbles. Thus, it is very important to identify the growing bubble when it is happening and not in an expost analysis.

Dealing with the challenge inherent in this exercise means properly identifying the fundamentals in the observed price acceleration so that the bubble can be anticipated and both investors and policy makers can act accordingly. This paper proposes a new mechanism that is able to compute ex-ante forecasting probabilities of price exuberance by combining state of the art recursive statistical analysis and standard asset pricing equilibrium theory. These h-step ahead probabilities follow from the estimation of a dynamic model that includes the asset abnormal returns and a test statistic that measures the likelihood of an explosive price behavior.

Some of the Monte Carlo simulations show that the fundamentals are essential to a better ex-ante prediction and that when bubbles are greater in length and scale our mechanism can predict for certain the last bubble up to five periods before the peak. An application to the Apple and NASDAQ Composite weekly and monthly data from 1990 to 2019 shows that price exuberance probabilities were greater than $85 \%$ and $90 \%$ three months and one month, respectively, before the "technological bubble" peak of 2000.

Our mechanism seeks to address two gaps in the literature of speculative bubbles. First, the incapability of existing econometric methods to differentiate between imperceptible fundamentals and price exuberance, as extensively discussed in Hamilton (1986) and Gurkaynak (2008). The two main drivers in our model provide a much clearer conclusion toward the existence of a bubble. What a statistic such as the Backward Supreme Augmented Dickey Fuller (BSADF) of Phillips et al. (2015 a,b) once identified as simply a non-stationary price behavior, now has a financial meaning through the asset pricing model. The second gap is the ability to capture what Shiller (2000) termed as a "feedback loop". According to this author, an important part of a speculative bubble resides in its social component, which generates a dynamic behavior that feeds the bubble until its inevitable collapse. Our model specification captures this process through the inclusion of a dynamic term such that the current value of the variable helps to determine the value of that same variable in the future. Finally, an essential part of our method involves generating learning expectations, which is another contribution to this literature.

The approach we propose is related to the strand of literature that models early-warning systems to anticipate vulnerabilities preceding systemic financial crises so that policymakers can take macroprudential measures. The early warning literature dates back earlier but found in the 1990s its most vigorous debate associated with banking, balance-of-payments and currency crashes (see, for example, Frankel \& Rose, 1996; Kaminsky \& Reinhart, 1999, and the more recent study by; Alessi \& Detken, 2011). In general, these models are based upon binary-choice methods that identify the false and missing warnings according to some loss function. We take a different route and focus attention on obtaining ex-ante forecasting probabilities of a bubble collapse given the fundamentals identified from a theoretical model in finance. In a different context, this is what recently Jang and Kang (2019) also proposed. These authors use a logit model to estimate the ex-ante probability of extreme negative returns of individual stocks and conclude that stocks with a high probability of crashes earn abnormally low returns.

This paper is structured as follows: In Section 2 we review some of the most influential work in the literature on speculative bubbles. Section 3 presents the definitions and theories underlying the new anticipation procedure. Section 4 provides a complete description of the new procedure, including a replica with simulated data. Section 5 offers an exhaustive Monte Carlo exercise in order to know the statistical properties of the approach for different data generating processes. In Section 6 the new procedure is applied to the Apple and NASDAQ Composite data, and Section 7 concludes.

\section{Literature review}

The literature concerning asset bubbles is quite extensive and the approaches can be roughly separated between theoretical economics and finance, statistical modeling, and testing. The idea of extrinsic variables leading asset prices is somewhat controversial. Most authors start with a common framework but usually arrive at considerably different conclusions about the bubble's existence. See, for example, Malkiel (2010), Scherbina (2013), Miao (2014), Brunnermeier and Schnabel (2015), Barberis, Greenwood, Jin, and Shleifer (2018), and Greenwood, Shleifer, and You (2019) for the meaning of the term "bubble" and the identification of some major historical examples of asset-price bubbles.

The emergence of rational expectations in the 1970's motivated authors like Shiller (1981), who derives theoretical limits for asset prices variation considering the underlying dividends (fundamentals). An empirical application with S\&P 500 data revealed an exaggerated volatility in the series, which the author does not link to price exuberance, implying the poor explanatory capability of the general asset pricing equation as theorized in Gurkaynak (2008). Using the same framework, Blanchard and Watson (1979) pioneered the concept of "periodically collapsing bubbles", stochastic processes that allow the common exponential growth process to periodically collapse according to some fixed probability. More recently Lee and Phillips (2016) set up an asset pricing model that accommodates the possibility of periods of price exuberance, characterizing systematic risk stemming from the possible occurrence of price bubbles, and Miao, Wang, and Xu (2015) present a Bayesian dynamic stochastic general equilibrium model of stock market bubbles and business cycles. Another important contribution is given in Hamilton (1986), in which price bubbles are caused by the explosive behavior in underlying unobserved fundamentals, like taxes, which are anticipated by economic agents.

By means of simulation analysis of price exuberance, Diba and Grossman (1988a,b) built two arguments against the existence of rational bubbles: First, if dividends and prices are stationary in first differences then bubbles are not present, otherwise even if differentiated $n$ times, the price process will still have an explosive behavior. Second, if prices and dividends are co-integrated then bubbles are not present. In response to this line of argumentation, Evans (1991) used simulations to demonstrate the reduced power of the standard unit root and co-integration tests when periodically collapsing bubbles, as in Blanchard (1982), are present, contrary to the standard bubble innovation process used by Diba and Grossman (1988a,b). When several bubbles collapse in the simulated sample, the process "appears" to be stationary. 
The paper by Evans (1991) is in an endeavor to find proper econometric tests for detecting asset price exuberance. A modified version of the basic ADF regression is developed in Hall, Sola, and Psaradakis (1999), by incorporating a Markov-Switching mechanism in which the parameters are allowed to change from a stationary to an explosive process resembling the behavior of periodically collapsing bubbles. Phillips, Wu, and Yu (2011) developed not only a recursive ADF statistic (SADF, using different sub-samples), but also a date stamp estimator for the eruption and collapsing periods of the bubble. The application to simulated data as in Evans (1991) revealed good power properties dealing with periodically collapsing bubbles but, nevertheless, it was still depended on the probability of collapse. An application to the NASDAQ Composite index revealed explosive behavior and dated reasonably well the "dotcom" exuberance.

Alongside the former approach, other tests have been developed to analyze the presence of bubbles in the data. Homm and Breitung (2012) review and compared five different statistics. An improved version of the SADF and a new date stamping methodology is presented in Phillips, Shi, and Yu (2015a,b). The main novelty is the rolling sub-sample scheme, in which instead of a fixed point in the beginning of the sample and the other one moving forward, now both points move, giving rise to the GSADF (Generalized Supreme $\mathrm{ADF}$ ). Besides the improved size distortions, the GSADF has greater power than its predecessor. The authors found that the new GSADF statistic is quite less sensitive to bubble collapses in the data. In an empirical application with the S\&P 500 price-dividend ratio from 1871 to 2010, both tests revealed explosive sub-periods but only the GSADF statistic could date stamp all episodes of asset price exuberance since 1900. Harvey, Leybourne, Sollis, and Taylor (2016) study the performance of the tests for explosive financial bubbles in the case of permanent volatility shifts in the innovation process. Alternative tests for speculative bubbles include those of Newey (1987), Flood and Hodrick (1990), Cuñado, Gil-Alana, and de Gracia (2005), Pavlidis, Paya, and Peel (2012), Breitung and Kruse (2013), Breitung (2014), Beckers (2015), Harvey, Leybourne, and Sollis (2015), Horie and Yamamoto (2016), and Astill, Harvey, Leybourne, and Taylor (2017). To date the start and end of asset price bubbles see also the work by Chong and Hurn (2015), Shi and Song (2016), Harvey, Leybourne, and Sollis (2017), and Harvey, Leybourne, and Whitehouse (2019).

The main drawback in this kind of literature is the lack of a complete framework able to explain the bubble phenomena. Models can represent different ways of capturing price explosion but not necessarily the price exuberance. The model presented in Branch and Evans (2011) provides a complete theoretical structure to explain the bubble phenomena. The beginning of exuberance occurs when investors underestimate price variance, which eventually exceeds a certain threshold and forces investors to sell off the asset due to utility loss. The former occurs as the investor constantly re-estimates his learning rule as in Evans and Honkapohja (2001), using a recursive least squares algorithm (Young, 2011).

\section{Theoretical foundations}

In this Section we review some theories in the literature that link the key elements that form the new procedure we propose. Here, we simply define the frameworks that are used in different fields. Afterwards, in Section 4.1, we explain the reasons for choosing these theories thus linking each one together for the particular purpose of computing ex-ante forecast probabilities of price exuberance in financial markets. First, we review a general asset pricing equation that explains the possibility of speculative bubbles under rational expectations. Second, we present the main idea of the adaptive learning theory and the usage of recursive methods in distinct fields. Third, we review the Capital Asset Pricing Model as an important equilibrium framework to determine abnormal returns in the market, and fourth, we define a method that is helpful in statistics and econometrics for testing for explosive processes. In Section 4, we show how these two quantities (abnormal returns and test statistic) are essential in our model to predict the probability of the presence of a bubble in the near future.

\subsection{Asset pricing models and bubbles}

The general asset pricing equation presented in Cochrane (2005) (p.6) yields as a solution the pricing equation $P_{t}=E_{t}\left[m_{t+1} x_{t+1}\right]$, where $P_{t}$ is the asset price at time $t, m_{t+1}$ represents the stochastic discount factor at $t+1, x_{t+1}$ represents a generic asset payoff, and $E_{t}$ represents the agent's expectation conditional on all available information up to period $t$. By assuming linearity at the utility function, we obtain the asset pricing equation presented in Lucas (1978).

$$
P_{t}=\left(\frac{1}{1+r}\right) E_{t}\left[P_{t+1}+D_{t+1}\right]
$$

where $r$ is a free-risk rate and $D_{t+1}$ is future dividends. Solving (1), the result becomes

$$
P_{t}=\sum_{i=0}^{n}\left[\left(\frac{1}{1+r}\right)^{i} E_{t}\left[D_{t+i}\right]\right]+\left(\frac{1}{1+r}\right)^{n} E_{t}\left\{P_{t+n}\right\}
$$

However, (2) is still dependent on the discounted expected price $n$ periods ahead from today, $\left(\frac{1}{1+r}\right)^{n} E_{t}\left[P_{t+n}\right]$, which may be the cause for speculative bubbles as shown later. For that reason, to "close" the model one takes $n \rightarrow+\infty$ yielding the fundamental stock price

$$
F_{t}=\sum_{i=1}^{+\infty}\left[\left(\frac{1}{1+r}\right)^{i} E_{t}\left[D_{t+i}\right]\right] .
$$


If the dividends follow a random walk stochastic process, $D_{t}=\mu+D_{t-1}+\varepsilon_{t}, \varepsilon_{t}{ }^{\sim} N\left(0, \sigma^{2}\right)$, (See, for example, Phillips et al. (2015a,b) and Evans (1991)), the solution is

$$
P_{t}=\left(\frac{1+r}{r^{2}}\right) \mu+\left(\frac{1}{r}\right) D_{t}
$$

The rise of speculative bubbles is consistent with the rational expectations hypothesis. This result is supported by the idea that any investor is willing to pay above its fundamental value as long as the price gets even higher. In particular, at each and every time period, price encapsulates both fundamentals and an extrinsic variable, so called "Bubble", $B_{t}$ :

$$
P_{t}=F_{t}+B_{t},
$$

as is, for example, the solution to the difference equation (1) (see (2) and (3) above). According to Kindleberger and Aliber (2005), the price exuberance will stop at a certain point in time, and it is therefore important to review some of the most common bubble processes employed in the theoretical literature: The alternative bubble specifications of Blanchard and Watson (1979) and Evans (1991).

The benchmark model for capturing exuberance behavior is the stochastic process developed in Blanchard and Watson (1979), also known as periodically collapsing bubbles. The specification of this process is given by

$$
B_{t+1}=\left\{\begin{array}{l}
\frac{1+r}{\pi} B_{t}+\varepsilon_{t}, \quad \text { with probability } \pi \\
\varepsilon_{t}, \text { with probability }(1-\pi)
\end{array} .\right.
$$

The bubble component follows one of two laws: With probability $\pi$, it can grow at a rate of $\frac{1+r}{\pi}$, which is larger than $(1+r)$, but at a certain point in time it may collapse, or it follows a white noise process, $\varepsilon_{t}$. The specification (6) is the basic structure of Evans (1991) process. However, it is now possible to control for two additional aspects besides the probability of a collapse $(\pi)$ :

$$
B_{t+1}=\left\{\begin{array}{l}
(1+r) B_{t} u_{t+1} \text { if } B_{t} \leq \alpha \\
{\left[\delta+\frac{(1+r)}{\pi} \theta_{t+1}\left(B_{t}-\frac{\delta}{(1+r)}\right)\right] u_{t+1} \quad \text { if } B_{t}>\alpha}
\end{array}\right.
$$

The parameters $\alpha>0$ and $\delta>0$ control for the bubbles' average length before they collapse and the frequency at which the bubbles erupt, respectively. In both processes, (6) and (7), the probability of a collapse occurring $(\pi \in[0,1])$ controls for the exuberance scale. Nevertheless, in (7) this parameter's influence in the equation acts through a Bernoulli trial $\left(\theta_{t+1}\right)$ occurring in each period which can allow the ongoing bubble $\left(B_{t}>\alpha\right)$ to continue even further or collapse the whole process back to the starting value $\delta$. The Evans' process is one of the most influential in this literature and shall be used later in the simulations Section.

\subsection{The "adaptive learning" theory}

The "Adaptive Learning" theory provides a more realistic framework when compared to Rational Expectations theory and its farfetched assumptions, namely the agent's complete knowledge and understanding of the economy. The underlying intuition in "Adaptive Learning" theory establishes that economic agents try to include the most recent information in forming their expectations by constantly updating them as new data are released. From a modeling perspective, this means that agents constantly re-estimate the set of structural parameters as new information becomes available instead of calibrating or simply assuming a constant value for the parameters. The reader can find a complete treatment of this subject in Bray (1982) and Evans and Honkapohja (2001).

Instead of estimating the model using the full sample approach in which parameters are uniquely determined, the estimation is performed through a set of updating equations that are fed when new data are available, thus yielding a whole new set of point estimates. See Evans and Honkapohja (2001) and Young (2011). The procedure starts with obtaining an expectation for a given economic variable $\left(Y_{t}^{e}\right)$ which depends on a set of other independent variables $\left(\mathbf{X}_{t}\right)$ and parameters estimates $\left(\widehat{\boldsymbol{\theta}}_{t-1}\right)$. This translates mathematically into

$$
Y_{t}^{e}=\Psi\left(\mathbf{X}_{t}, \widehat{\boldsymbol{\theta}}_{t-1}\right)
$$

for some function $\Psi$. The main difference between Rational Expectations and Adaptive Learning is on how agents obtain estimates for $\widehat{\boldsymbol{\theta}}_{t-1}$. Instead of $\widehat{\boldsymbol{\theta}}$ fixed, the agents constantly update their estimates with new data according to some algorithm:

$$
\widehat{\boldsymbol{\theta}}_{t}=\widehat{\boldsymbol{\theta}}_{t-1}+\gamma Q\left(t, \widehat{\boldsymbol{\theta}}_{t-1}, \mathbf{X}_{t}\right)
$$

where $\gamma$ is a measure of how algorithm (9) absorbs newly available data and $Q$ represents the updating equation specification. The relevance of the "Learning" approach is justified when market conditions start to reveal the presence of a speculative bubble, as we shall see in the next Sections. 


\subsection{CAPM equilibrium model}

A very important part of the proposed anticipation mechanism includes the use of an asset pricing model to provide a financial explanation for the observed price explosiveness. The Capital Asset Pricing Model (CAPM) presented in Sharpe (1964) is the most sought out equilibrium model in finance. In basic terms this model yields the equilibrium rate of return of a given security under a set of assumptions. The most notable feature is that it specifies that all market participants should maximize their reward to volatility ratio, which is the same as stating that they build their portfolios as developed in Markowitz (1952).

The CAPM's main specification is given by

$$
E_{t}\left[R_{i, t}\right]^{\mathrm{CAPM}}=r_{f}+\beta\left(E_{t}\left[R_{M, t}\right]-r_{f}\right),
$$

where $E_{t}\left[R_{i, t}\right]^{\mathrm{CAPM}}$ represents the stock $i$ equilibrium return at time $t, \beta \equiv \frac{\operatorname{Cov}\left(R_{i, t}, R_{M, t}\right)}{\operatorname{Var}\left[R_{M}\right]}$ is a measure of risk that shows the contribution of the asset's volatility to the total market volatility at time $t, r_{f}$ is a risk-free rate of return, and $R_{M, t}$ is the total market return at time $t$. The specification (10) has a serious limitation: the market return is not observable, in theory. In Sharpe (1963) the author proposes an alternative approach to the Markowitz (1952) algorithm, which is also a commonly used solution to the CAPM's theoretical Market portfolio. In the Single Index Model (SIM) we have the following regression:

$$
R_{i, t}-r_{f}=\alpha+\beta\left(R_{I, t}-r_{f}\right)+\varepsilon_{t}, \quad \varepsilon_{t}^{\sim} N\left(0, \sigma^{2}\right),
$$

where $\alpha$ and $\beta$ are fixed parameters and $R_{I, t}$ is the return of a benchmark portfolio at time $t$, which can be used to proxy the CAPM's Market portfolio. ${ }^{2}$ As one would expect, $\beta$ is identical to the one in specification (10) and $\alpha$ is the CAPM's abnormal return prediction for the stock $i$.

\subsection{The backward supreme ADF statistic (BSADFS)}

Another very important ingredient of the proposed anticipation mechanism is how to capture the observed price acceleration. In our view, the most effective way in statistical terms to complete this task is to use the Backward Supreme Augmented Dickey Fuller Statistic (BSADFS) date stamp strategy developed in Phillips et al. (2015a,b). The BSADFS selects the highest value of the standard Augmented Dickey Fuller test in various increasing sub-samples. From that sequence of statistics it is possible to estimate the beginning of exuberance, $\widehat{r}_{e}$ (the first period for which the BSADFS is larger than the simulated critical value) and its ending, $\widehat{r}_{f}$ (the first period for which the BSADFS is smaller than the simulated critical value).

The estimated beginning and ending of a bubble is given by definitions (12) and (13), respectively:

$$
\begin{aligned}
& \widehat{r}_{e}=\inf _{r \in[0,1]}\left\{r: \operatorname{BSADFS}_{r}\left(r_{0}\right)>s c v_{r}^{\eta_{T}}\right\}, \\
& \widehat{r}_{f}=\inf _{\left.r \in \widehat{r}_{e}+\xi \log (T) / T, 1\right]}\left\{r: B S A D F S_{r}\left(r_{0}\right)<s c v_{r}^{\eta_{T}}\right\},
\end{aligned}
$$

where $\widehat{r}_{e}$ and $\widehat{r}_{f}$ are defined as fractions of the sample size $T$, i.e., $r=t_{0} / T$, for a beginning or ending exuberance period $t_{0}$. The value given by $r_{0}$ represents the percentage of the total sample used to initiate the calculation of the BSADF. The BSADF statistic performs a comparison between backward expanding sub-samples in which the starting point varies from 0 to $\left(r-r_{0}\right)$. One can obtain the exact estimated period for the bubble outbreak and its respective termination by calculating $\widehat{r}_{e} T$ and $\widehat{r}_{f} T$. Finally, $s c v_{r}^{\eta_{T}}$ represents a simulated critical value that depends on the given significance level $\left(\eta_{T}\right)$ and the total sample size (T). See also Phillips et al. (2011), Homm and Breitung (2012), and Phillips and Shi (2018) for dating speculative bubbles in stock markets.

\section{A new bubble anticipation mechanism}

The concepts and definitions presented above compose the new proposed system capable of anticipating a speculative bubble. The new anticipation mechanism is described in this section, and for ease of reference shall be called NBA mechanism.

\subsection{Designing the NBA mechanism}

The novelty of this paper is that we can compute ex-ante forecast probabilities of price exuberance by combining recursive statistical analysis and asset pricing equilibrium theory. The goal behind the mechanism is to generate a one step ahead probability forecast for the existence of a speculative bubble by means of a dynamic probit model. The choice for a binary response model to a problem such as this one is justified by our inability to directly observe an ongoing bubble in practice. In fact, we can observe only a sudden phenomenon of great acceleration in the security price as shown in Franses (2016) and that can be easily captured by the BSADF statistic, as

${ }^{2}$ The benchmark is very often a Broad Equity Index like the NASDAQ Composite. 
demonstrated in Phillips et al. (2015a,b). The main challenge is on how to differentiate between explosive unobservable fundamentals and a speculative bubble (Hamilton, 1986).

The NBA mechanism tackles this problem by designing the following approach that links each theory in Section 3 together. Given the information available, the agent observes in a given period $t$ the asset price $P_{t}$ and formulates a subjective expectation according to the learning rule in equations (8) and (9), i.e. a recursive mean for $P_{t}$. Now, according to equation (5), he/she knows that at each point in time the observed price $P_{t}$ is nothing but a composite of two quantities: fundamentals and bubble. Thus, to obtain an accurate assessment of exuberance he/she needs a good proxy for both variables. To infer about price explosion, typical of a bubble, the agent uses the BSADF statistic to pinpoint exactly the initial and final periods of price explosion defined in equations (11) and (12), respectively. Nonetheless, a definite conclusion towards the existence of a bubble is not yet possible because prices can be driven by fundamentals. That is, finding support for nonstationarity needs to be complemented by the inclusion of some measure of its fundamental value. In this respect, the agent proxies fundamentals by comparing its subjective expectation with the CAPM equilibrium return, given in equation (10), and from that he/she estimates the correspondent abnormal return $\left(Y_{t-1}^{*}\right.$ in equation (14) below). For him/her, this is nothing more than a measure of the difference between the agent's perception of the fair return for the asset at time $t$ and the appropriate equilibrium model, in this case the CAPM. If the agent feels that the market is showing exuberance then the abnormal returns should explain the probability of existing a bubble (c.f. validated probability in equations (19) and (20) below). Beyond the recursive nature of the whole procedure, this approach of estimating the abnormal returns is coherent with the Adaptive Learning Theory (Section 3.2) because the agent's learning procedure (learning rule) regarding the observed asset is discounted from the insight of the chosen asset pricing model.

In sum, recursively, we make use of an asset pricing equilibrium model and a non-stationarity test statistic and collect their predictions, in terms of abnormal returns and likelihood of an explosive behavior, under the same econometric model specification (dynamic probit). From that model, and for each period, compute the conditional probability for the existence of a speculative bubble at the next moment. Thus, what previously in the literature was once identified as simply non-stationary price behavior, now has a financial meaning through the asset pricing model. Moreover, the model specification captures the dynamic behavior that feeds the bubble until its inevitable collapse.

\subsection{The NBA procedure}

In the NBA mechanism, the main econometric model ${ }^{3}$ is given by:

$$
\left\{\begin{array}{c}
\text { bubble }_{t}^{*}=\beta_{1}+\beta_{2} \Upsilon_{t-1}^{*}+\beta_{3} D_{t-1}^{\mathrm{BSADFS}}+\varepsilon_{t}, \\
D_{t}^{\mathrm{BSADFS}}=I\left(\text { bubble }_{t}^{*}>0\right)
\end{array} \quad \varepsilon_{t}^{\sim} N(0,1),\right.
$$

where the latent variable, bubble $e_{t}^{*}$, associated with the observed price of a particular asset, is a function of the asset's abnormal return estimated from a given asset pricing model, $\Upsilon_{t-1}^{*}$, and $D_{t-1}^{\mathrm{BSADFS}}$, a dummy variable accounting for price's explosiveness:

$$
D_{t}^{\mathrm{BSADFS}}=\left\{\begin{array}{l}
1 \text { if } \mathrm{BSADFS}_{t}>s c v^{\mathrm{BSADFS}} \\
0 \text { if } \mathrm{BSADFS}_{t} \leq s c v^{\mathrm{BSADFS}} .
\end{array}\right.
$$

here, $\mathrm{BSADFS}_{t}$ is the BSADF statistic calculated using the price observed data up to time $t, s c v^{\mathrm{BSADFS}}$ represents the simulated critical value for a given significance level, and $\varepsilon_{t}$ is a Normal distributed error.

The indicator function, $I(\cdot)$, assumes the value of 1 if, based on the BSADFS, the unobserved bubble exists (i.e, bubble $e_{t}^{*}>0$ ) and the value of zero if the bubble does not exist (i.e, bubble $\left.e_{t}^{*} \leq 0\right)$. The intuition is similar to that in equation (5): if bubble* assumes a nonpositive value, which in practice means it does not exist $\left(B_{t}=0\right)$, then the asset price is equal to the respective fundamental price $\left(P_{t}=F_{t}\right)$.

Also importantly, the specification given in (14) provides an answer to the following question: what is the estimated probability of tomorrow's price containing a bubble, given today's estimated abnormal return and the value of the BSADFS, as a measure of price explosiveness? Defining $\boldsymbol{\Omega}_{\mathbf{t}-1}^{\prime} \equiv\left(1, \Upsilon_{t-1}^{*}, D_{t-1}^{\mathrm{BSADS}}\right)$, and $\boldsymbol{\beta}^{\prime} \equiv\left(\beta_{1}, \beta_{2}, \beta_{3}\right)$ and assuming normally distributed disturbances, $\varepsilon_{t}^{\sim} N(0,1)$, the estimated conditional probability of a bubble occurring one period ahead is given by $\Phi\left(\widehat{\boldsymbol{\beta}}\right.$ ' $\left.\boldsymbol{\Omega}_{\mathbf{t}-1}\right)$, where $\Phi(\cdot)$ is the Normal Cumulative Distribution Function. The estimation and inference approach of the model (14) is similar to the case of the standard probit model. See de Jong and Woutersen (2011) and Nyberg (2010) for the properties of the dynamic binary choice model.

The choice for gaussianity is for sake of simplicity but at the same time it is an assumption that the Monte Carlo simulations corroborate in part. There is no way we can derive the distribution function $P\left[\mathrm{BSADFS}_{\mathrm{t}}>s c v^{\mathrm{BSADFS}} \mid \Upsilon_{t-1}^{*}, \mathrm{BSADFS}_{t-1}\right] \mathrm{Phillips}$ et al. (2015a,b) derive the asymptotic distribution of the BSADFS statistic under the null hypothesis of unit root which is quite different from the one we are modelling: it is not under any testing assumption and it is conditional on the observed abnormal returns. In the model we propose,

\footnotetext{
${ }^{3}$ Following a suggestion of a referee (whom we thank), we also considered replacing the dummy variable by the implied probability from the BASDF test statistic (ratio of the statistic against the simulated critical values) at the RHS of the model. From the Monte Carlo simulations, we conclude that there are no gains from doing it.
} 


$$
\begin{gathered}
P\left[\text { bubble }_{t}^{*}>0 \mid \Upsilon_{t-1}^{*}, D_{t-1}^{\mathrm{BSADFS}}\right] \\
=P\left[\mathrm{BSADFS}_{t}>s c v^{\mathrm{BSADFS}} \mid \mathrm{\Upsilon}_{t-1}^{*}, \text { BSADFS }_{t-1}\right] \\
=\Phi\left(\beta_{1}+\beta_{2} \Upsilon_{t-1}^{*}+\beta_{3} D_{t-1}^{\mathrm{BSADFS}}\right),
\end{gathered}
$$

with $\beta_{1}$ making sure that $\varepsilon_{t}$ has zero mean and the unit variance is to guarantee identification of $\beta$. As we will see later, the Monte Carlo exercise shows that our NBA procedure works properly in picking the bubbles which makes us conjecture that the Probit model (gaussianity) is a fair assumption to take.

The NBA procedure initiates with the estimation of the abnormal returns, $\widehat{\Upsilon}_{t-1}$, and the BSADFS. The first component is obtained by the difference between the investor's subjective expectation of the asset return and the equilibrium return given by an asset pricing model, like the CAPM of Sharpe (1964). The second component provides the exuberance timing estimators $\left(\widehat{r}_{e}\right.$ and $\left.\widehat{r}_{f}\right)$ from which we generate the dummy variable that proxies for a speculative bubble, $D_{t}^{\mathrm{BASDF}}$. From the estimation of (14) one obtains three different point estimates: the regression intercept, $\widehat{\beta_{1}}$, the contribution of the abnormal return to the probability of exuberance, $\widehat{\beta_{2}}$, and the contribution of the price acceleration to the probability of exuberance, $\widehat{\beta_{3}}$. Moreover, the recursive procedure provides an estimated conditional probability of a speculative bubble occurring one period ahead from the moment the estimation took place

$$
P_{t}\left[D_{t+1}^{\mathrm{BSADS}}=1\right]=\Phi\left[\widehat{\boldsymbol{\beta}}{ }_{t} \boldsymbol{\Omega}_{\mathbf{t}}\right]
$$

The recursive nature of the NBA approach implies the re-estimation of (14) each time a new observation is available, inducing timevarying coefficients $\widehat{\boldsymbol{\beta}}_{t}$ such that (possibly) some of the coefficients are not statistically significant throughout the whole sample. To see how the NBA mechanism works in full detail, we next present some simulated data according to our setup.

\subsection{Illustrating the NBA mechanism in practice}

\subsubsection{Generating price exuberance}

The whole procedure starts by simulating two different prices, one for the security and another for the benchmark index (See Table 1 for the choice of the parameters when generating the time series and for the entire mechanism in general.).

The fundamental components are simulated according to the law given by (4), and the price by (5), in which the bubble process is generated according to (7). The discount factor was deemed constant and estimated using the 6 Month Treasury Bills monthly data from 1960 to 2014. The simulation final total sample size is smaller than $T$ due to two factors: the BSADFS takes the initial $\left(r_{0} T-1\right)$ observations, in which $r_{0}=0.01+\frac{1.8}{\sqrt{T}}$, and due to the recursive scheme of the NBA mechanism we start at observation $20 \% \times T$. In Figs. 1 and 2 , we see three major peaks. There is one at the beginning of the sample, another one around the 100th period, and a final one around the 400th period.

\subsection{2. "Adaptive learning", abnormal returns, and measuring explosiveness with BSADFS}

The next step is based on the recursive estimation of the security's abnormal return. For this we consider the CAPM equilibrium return and the subjective return prediction results from the adaptive learning theory. In particular, for each period $t$, the abnormal return is estimated using the equation

$$
\widehat{\Upsilon}_{t}^{*}=\overline{R_{t}}-E\left[R_{t}\right]^{\mathrm{CAPM}}
$$

where $\overline{R_{t}}$ is the asset mean return until time $t$ according to $\overline{R_{t}}=\bar{R}_{t-1}+\gamma\left[R_{t}-\bar{R}_{t-1}\right]$ for a constant gain parameter $\gamma$ and $R_{t+1}=\frac{P_{t+1}-P_{t}}{P_{t}}$ and $E\left[R_{t}\right]^{\mathrm{CAPM}}$ follows from the estimation of the CAPM.

In intuitive terms, the abnormal return, represented in Fig. 3, is the difference between the investor's expectation and the asset fundamentals represented by the CAPM equilibrium prediction, each of the two being updated every time new data become available. The huge peaks observed in the abnormal returns are a direct result from the learning rule. Estimating expectations with constant gains

Table 1

The NBA mechanism - parameters for simulations.

\begin{tabular}{ll}
\hline Sample Size & $T=1000$ \\
NBA Initial Sample & $20 \% \times T=200$ \\
Security Price & $P_{0}^{S}=F_{0}^{S}=100 \quad D_{0}^{S}=1.3 \quad \mu=0.0000746 \quad \sigma_{D^{S}}^{2}=0.0003148$ \\
Index Price & $P_{0}^{I}=F_{0}^{I}=1000 \quad D_{0}^{I}=10 \quad \mu=0.0373 \quad \sigma_{D^{I}}^{2}=0.1574$ \\
D.G.P (Evans) & $B_{0}=0, \alpha=1, \delta=1, \pi=0.85$ \\
Risk Free Rate & $r=5 \%$ \\
BSADF Significance Level & $\eta_{T}=5 \%$ \\
Constant Gains & $\gamma=0.2$ \\
Asset Pricing Model Contribution & $\beta_{2} \neq 0$ \\
P-Value Validity & Yes \\
\hline
\end{tabular}




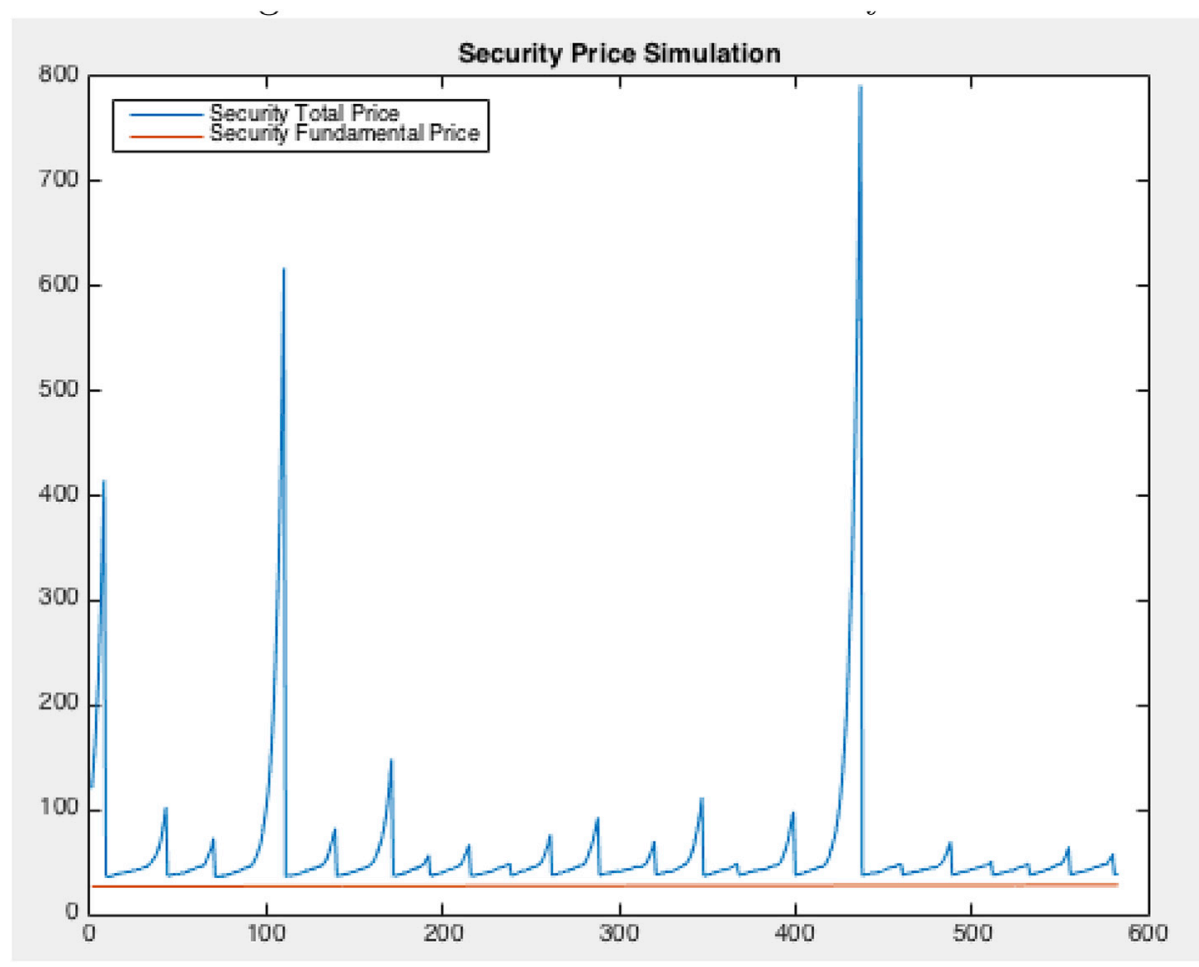

Fig. 1. Simulation of the security price.

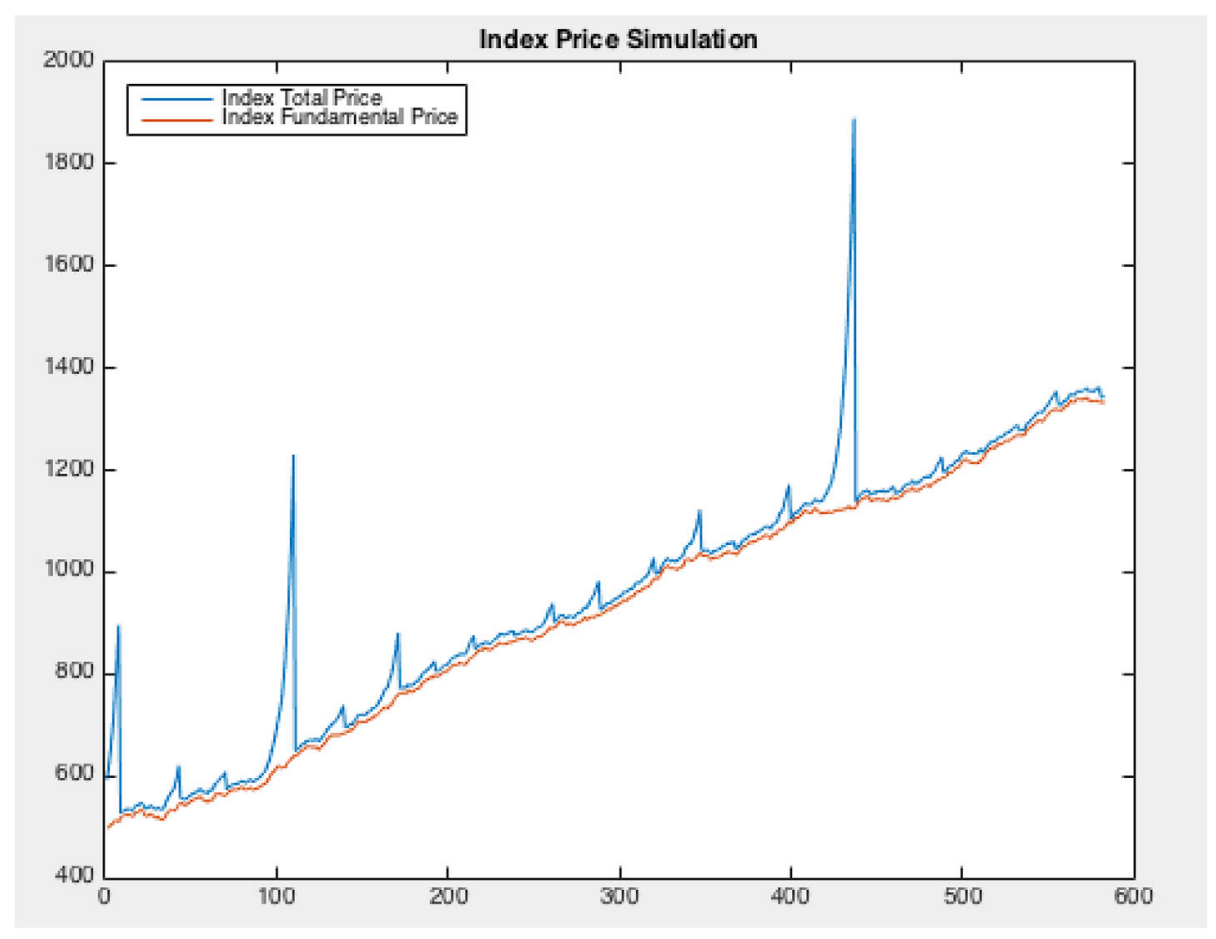

Fig. 2. Simulation of the benchmark price.

is essential to the NBA mechanism because it is an effective way to incorporate the significant structural breaks induced by price exuberance in the equilibrium variables. 


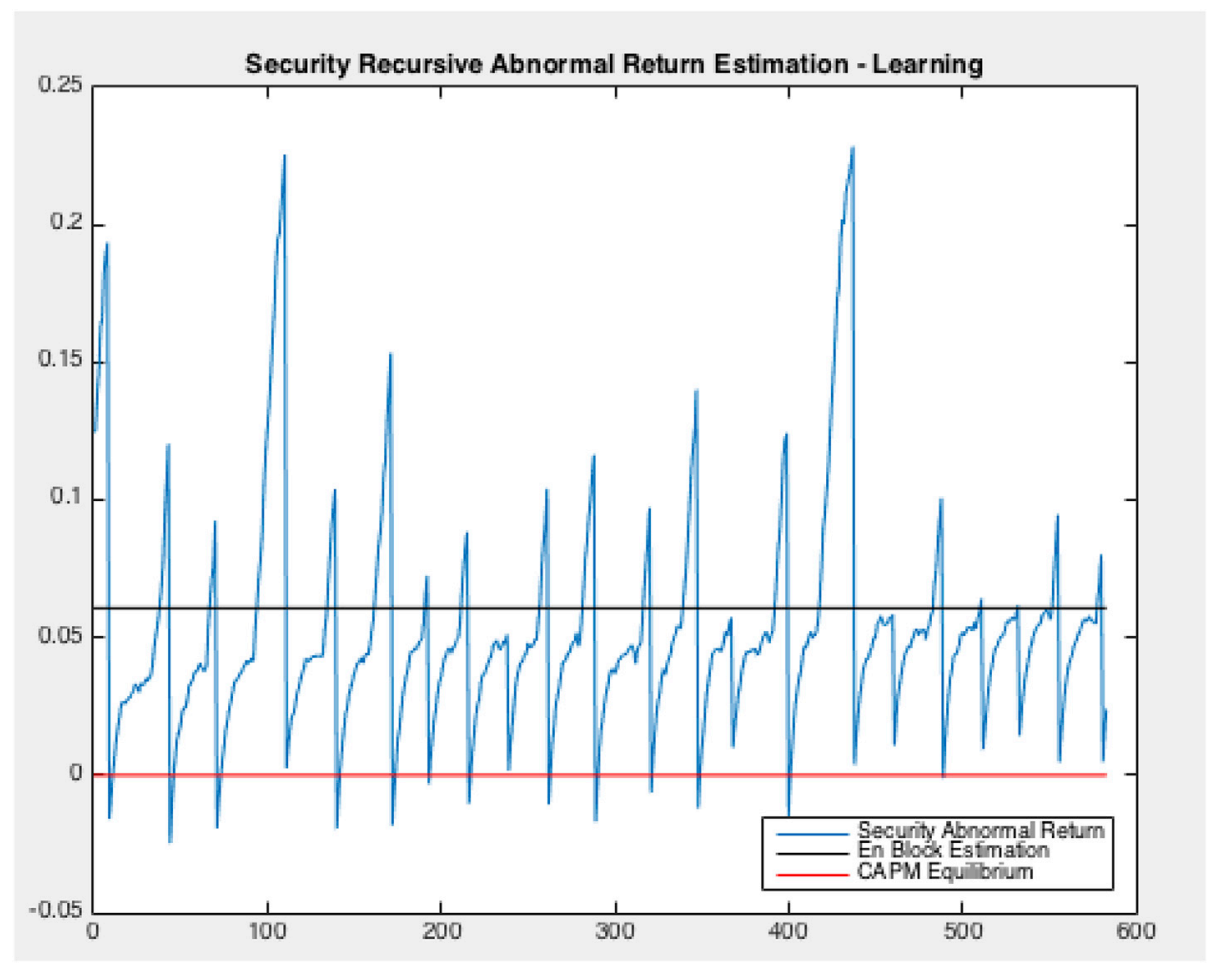

Fig. 3. Simulation of abnormal returns.

The next step is to measure the current price $P_{t}$ acceleration using the BSADFS. As will be demonstrated in the next Section, feeding this information to the NBA mechanism significantly improves the ability to predict exuberance. Fig. 4 exhibits maximum values in the

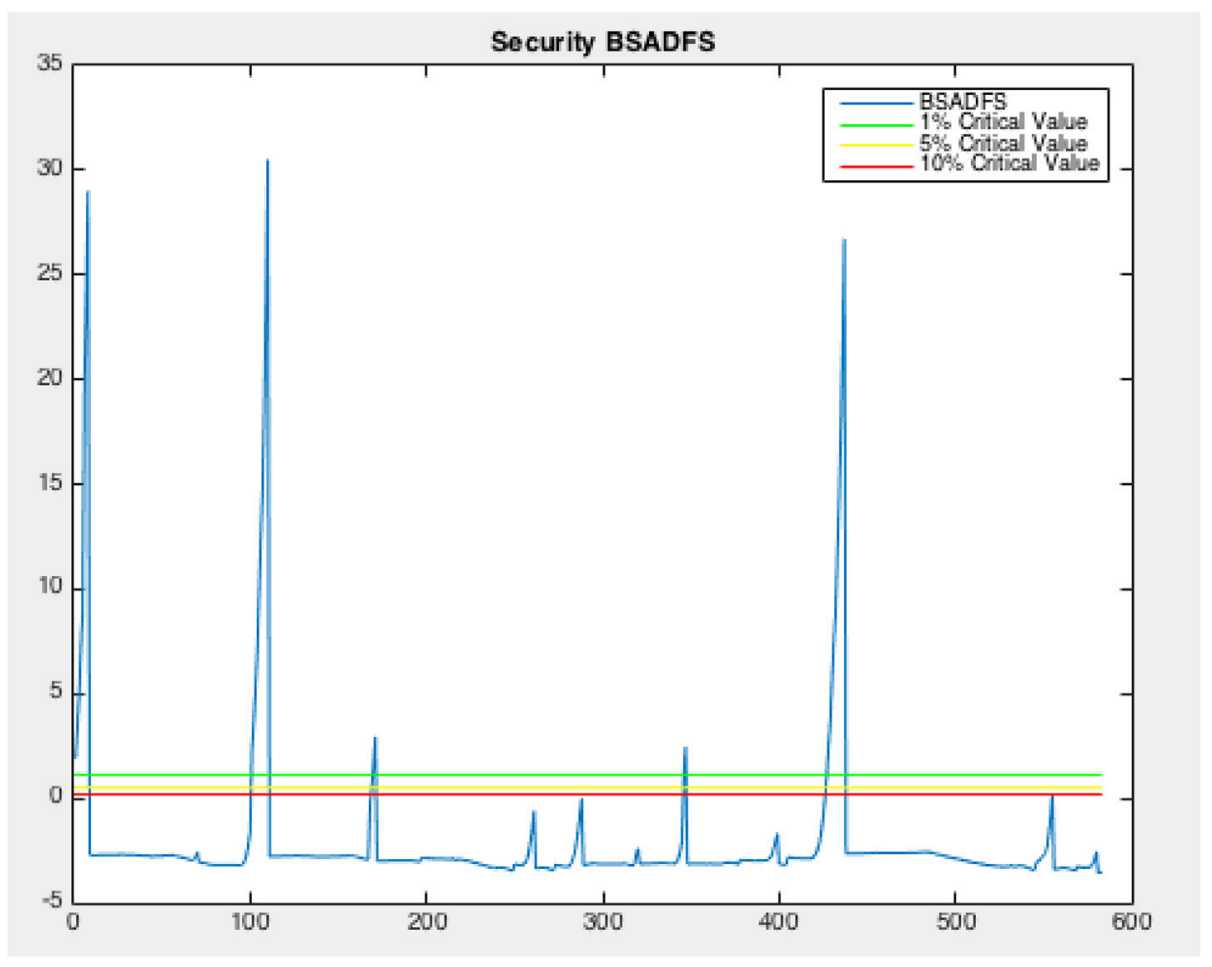

Fig. 4. BSADF statistic applied to simulated data. 
quoted periods, which greatly surpass the $1 \%$ critical value, implying extreme price accelerations similar to those observed in real world events. Recall that from the BSADFS we obtain $\widehat{r}_{e}, \widehat{r}_{f}$ and from that we construct the dummy variable identifying a period of bubble.

\subsubsection{Dynamic probit estimation}

In the last stage, the data signals obtained previously are used to estimate the model (14). The three estimated coefficients fluctuate around the full-sample point estimate $\left(\widehat{\beta_{1}}\right.$ around $-3.4, \widehat{\beta_{2}}$ around 16 , and $\widehat{\beta_{3}}$ around 1.8$)$ and, noticeably, the parameter's sharp increase at the referenced periods results from the occurrence of the bubbles.

In each period, the NBA mechanism yields a one step ahead probability. However, this result is meaningful if and only if all parameters are statistically significant, because it is not rational for an investor to perform changes in his/her portfolio if the underlying decision model is lacking good statistical properties. For this reason, we consider two types of probability: the standard one given by $P_{t-1}\left[D_{t}^{\mathrm{BSADFS}}=1\right]$ (see Fig. 5) and a validation probability measure defined by

$$
P_{t-1}^{*}\left[D_{t}^{\widehat{\mathrm{BADFS}}}=1\right]=\left\{\begin{array}{c}
P_{t-1}\left[D_{t}^{\widehat{\mathrm{BSADF}}}=1\right] \text { if } \text { Validity }_{t-1}=1 \\
0 \text { if Validity } \\
t-1
\end{array}\right.
$$

where

$$
\text { Validity }_{t-1}=\left\{\begin{array}{l}
1 \text { if } \operatorname{Pvalue}\left(t_{\widehat{\beta}_{1}}, t_{\widehat{\beta}_{2}}, t_{\widehat{\beta}_{3}}\right) \leq 10 \% \\
0 \text { if } \operatorname{Pvalue}\left(t_{\widehat{\beta}_{1}}, t_{\widehat{\beta}_{2}}, t_{\widehat{\beta}_{3}}\right)>10 \%
\end{array}\right.
$$

here, Pvalue $\left(t_{\widehat{\beta}_{1}}, t_{\widehat{\beta}_{2}}, t_{\widehat{\beta}_{3}}\right) \leq 10 \%$ means that all $\beta^{\prime} s$ are statistically significant at a $10 \%$ level, say, in period $t-1$. The probability $\widehat{P}_{t-1}^{*}$ is the one to be considered. From Fig. 6 we conclude that the NBA procedure yields high probabilities one period before the referenced peaks. Taking into account that it is a "validated" probability, one can state that the NBA mechanism has successfully anticipated the three bubbles generated in this simulation exercise.

The difference between $\widehat{P}_{t-1}^{*}$ and $\widehat{P}_{t-1}$ is due to the P-Value of the $t$-test associated with the abnormal return (all the other parameters are statistically significant for all periods). This fact leads to a very important conclusion: if the observed abnormal return does not have statistical significance in the model, then it is impossible for the NBA mechanism to fully distinguish and purge the fundamentals from the observed price. Thus, it leaves no choice but to ignore the one step ahead probability.

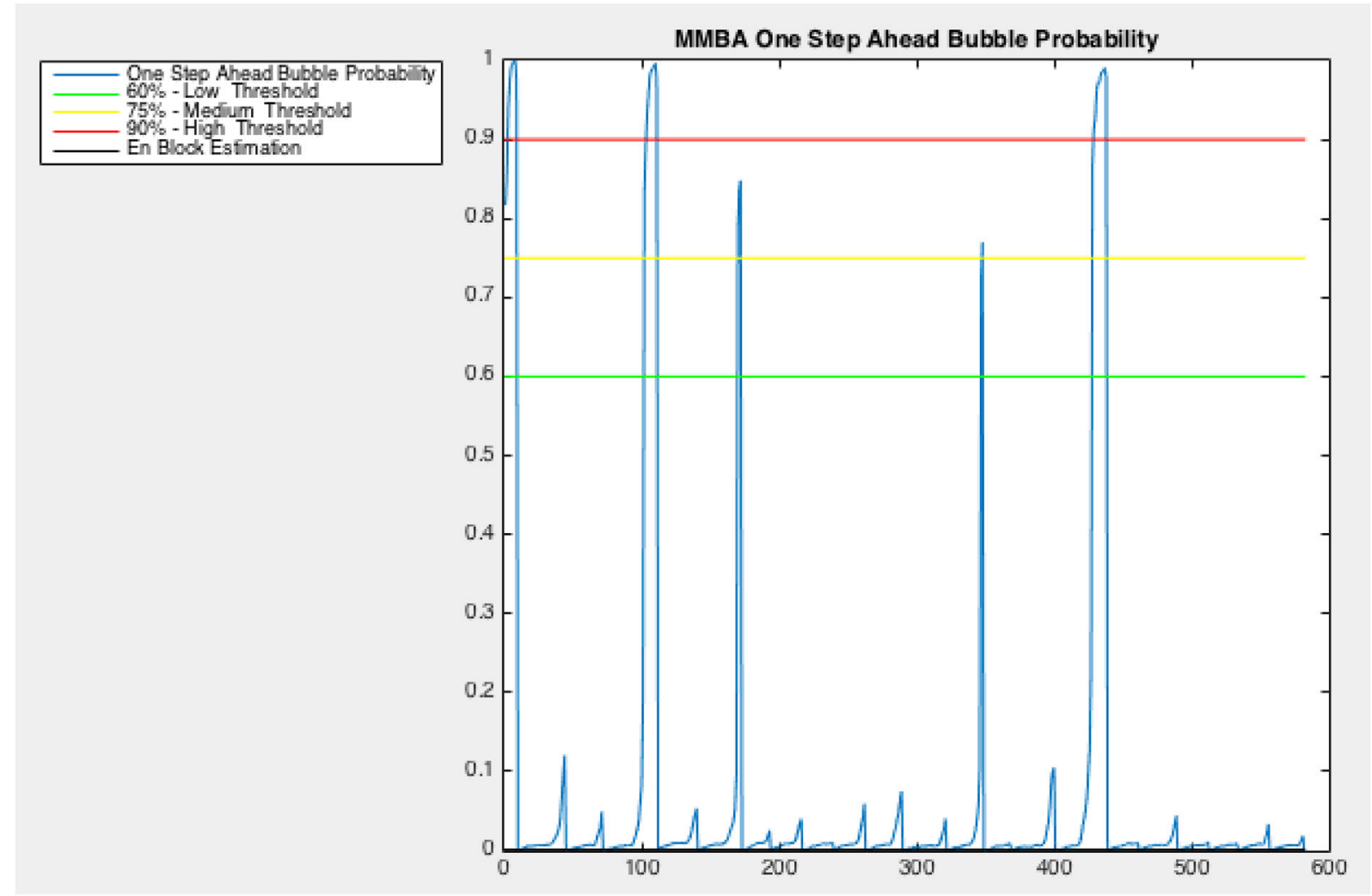

Fig. 5. Bubble probability (simulated data). 


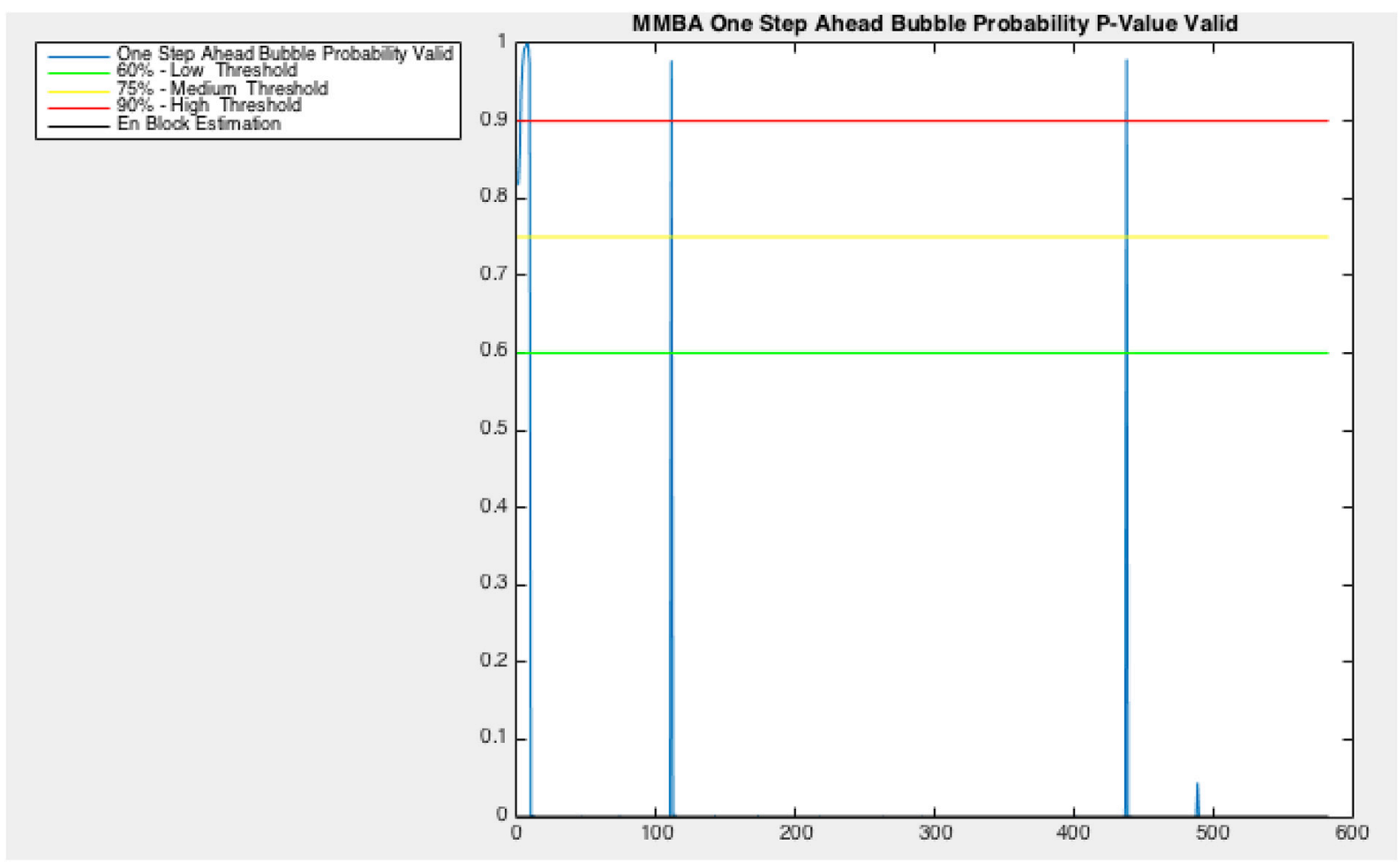

Fig. 6. Bubble validated probability (simulated data).

\section{Monte Carlo results}

In this Section, an exhaustive Monte Carlo exercise is conducted to investigate the NBA mechanism statistical properties. The default set of parameters is in Table 1, but throughout this Section we perform simulations with alternative data generating processes. The total number of replicas is 100 and from that we calculate three statistical measures: Mean $(\bar{X})$, Standard Deviation $(\Sigma(X))$, and Median $(\operatorname{Med}(X))$. The reference probability for measuring the NBA's anticipation capacity is the $90 \%$ threshold.

All tables have results that are divided into 5 blocks. First are some general descriptive statistics with the purpose of providing a bird's eye view of the results. Here we have the valid NBA predictions in percentage of the total sample size $\left(P^{*} / T\right)$; the number of bubbles per simulation $\left(\#\left(B_{1, \ldots, T}\right)\right)$; the number of predictions considering all bubbles in the sample, per simulation $\left.\left(\# a\left(P_{t-1}^{*}\left[B_{t}\right]\right] \geq 60 \%\right)\right)$; and the number of predictions of the last bubble in the sample, per simulation $\left(\# e\left(P_{T-1}^{*}\left[B_{T}\right] \geq 60 \%\right)\right)$. In the second block we have the percentage of $h$ - step ahead predictions with probability greater than $W \%$, with $h=1, \ldots, 5$ and $W=$ $60,75,90$, considering all bubbles in the sample $\left(P_{t-h}^{*}\left[B_{t}=1\right] \geq W \%\right)$. The third block is the same as the second but considering only the last bubble in the sample. In the fourth block we have the probability of a bubble occurring $h$ - steps prior to the peak, considering all bubbles in the sample $\left(P_{t-1}^{*}\left[B_{t}\right]\right)$. The fifth block is the same as the fourth but considering only the last bubble in the sample.

\subsection{The sample size}

An important aspect in empirical work is how the procedure responds to different sample sizes. Table 2 provides the results for various sample sizes, $T$.

An obvious conclusion is that the procedure performs better with larger sample sizes, a consequence also of having fewer bubbles in small samples ( $T=200, T=400)$. There is an average of 1.5 and 5 bubbles for the smallest $(T=200)$ and the largest sample size $(T=$ 1000 ), respectively. In fact, one can observe a huge difference in valid probabilities when comparing $T=200$ against $T=1000$, where $8.20 \%$ compares to $84.95 \%$, respectively. The NBA's need for a large sample size does not typically constitute an issue for financial data.

The new mechanism also reveals a desirable learning dynamic, resulting in higher predictive power toward the last bubble in the sample. The simulations showed an average of $77.38 \%$ for the last bubble against $66.44 \%$ when considering all bubbles in the sample, for a one step ahead probability greater than $60 \%$. Another important feature for large sample sizes is the mechanism's ability to capture significant probabilities until the fifth period before the bubble peak, which helps in executing a proper surfing strategy. For $T=1000$, more than half of the time the procedure yields a probability greater than $60 \%$ five periods before the bubble peak. When we consider $T=200$, there is a drop to $24.35 \%$. Finally, it is possible to notice that the one step ahead probability converges toward the average value of $70 \%$ as the sample size increases. 
Table 2

Monte Carlo simulation - the sample size.

\begin{tabular}{|c|c|c|c|c|c|c|c|c|c|c|c|c|}
\hline \multirow{2}{*}{$\frac{\text { Parameters }}{\text { Statistics }}$} & \multicolumn{3}{|c|}{$T=200$} & \multicolumn{3}{|c|}{$T=400$} & \multicolumn{3}{|c|}{$T=600$} & \multicolumn{3}{|c|}{$T=1000$} \\
\hline & $\bar{X}$ & $\Sigma X$ & $\operatorname{Med}(X)$ & $\bar{X}$ & $\Sigma X$ & $\operatorname{Med}(X)$ & $\bar{X}$ & $\Sigma X$ & $\operatorname{Med}(X)$ & $\bar{X}$ & $\Sigma X$ & $\operatorname{Med}(X)$ \\
\hline$P^{*} / T$ & 8.20 & 11.34 & 4.00 & 30.71 & 28.85 & 24.00 & 57.02 & 30.84 & 62.00 & 84.95 & 16.42 & 91.63 \\
\hline$\#\left(B_{1}, \ldots, T\right)$ & 1.41 & 0.53 & 1.00 & 2.67 & 1.05 & 3.00 & 3.15 & 1.19 & 3.00 & 4.98 & 1.79 & 5.00 \\
\hline$\# a\left(P_{t-1}^{*}\left[B_{t}\right] \geq 60 \%\right)$ & 0.50 & 0.57 & 0.00 & 1.22 & 1.01 & 1.00 & 1.98 & 0.96 & 2.00 & 3.23 & 1.31 & 3.00 \\
\hline$\# e\left(P_{T-1}^{*}\left[B_{T}\right] \geq 60 \%\right)$ & 0.40 & 0.49 & 0.00 & 0.60 & 0.49 & 1.00 & 0.82 & 0.39 & 1.00 & 0.77 & 0.42 & 1.00 \\
\hline \multicolumn{13}{|c|}{ All Sample Bubbles Statistics } \\
\hline$P_{t-1}^{*}\left[B_{t}=1\right] \geq 60 \%$ & 36.52 & 43.08 & 0.00 & 49.42 & 38.18 & 50.00 & 66.72 & 29.46 & 66.67 & 66.44 & 23.08 & 66.00 \\
\hline$P_{t-1}^{*}\left[B_{t}=1\right] \geq 75 \%$ & 35.65 & 42.80 & 0.00 & 48.17 & 39.10 & 50.00 & 66.21 & 29.16 & 66.67 & 62.88 & 25.05 & 64.00 \\
\hline$P_{t-1}^{*}\left[B_{t}=1\right] \geq 90 \%$ & 33.04 & 41.83 & 0.00 & 40.11 & 37.69 & 33.33 & 58.10 & 30.37 & 50.00 & 54.83 & 26.76 & 57.00 \\
\hline$P_{t-2}^{*}\left[B_{t}=1\right] \geq 60 \%$ & 33.48 & 41.74 & 0.00 & 47.97 & 37.31 & 50.00 & 62.69 & 31.23 & 66.00 & 59.95 & 24.98 & 60.00 \\
\hline$P_{t-2}^{*}\left[B_{t}=1\right] \geq 75 \%$ & 33.48 & 41.74 & 0.00 & 45.33 & 38.05 & 50.00 & 61.67 & 31.64 & 66.00 & 56.60 & 26.17 & 58.00 \\
\hline$P_{t-2}^{*}\left[B_{t}=1\right] \geq 90 \%$ & 27.83 & 39.29 & 0.00 & 33.25 & 36.01 & 25.00 & 51.82 & 31.72 & 50.00 & 49.07 & 27.68 & 50.00 \\
\hline$P_{t-3}^{*}\left[B_{t}=1\right] \geq 60 \%$ & 31.30 & 41.60 & 0.00 & 38.67 & 36.60 & 41.67 & 58.41 & 32.39 & 60.00 & 55.11 & 25.85 & 60.00 \\
\hline$P_{t-3}^{*}\left[B_{t}=1\right] \geq 75 \%$ & 29.57 & 40.77 & 0.00 & 36.86 & 36.42 & 33.33 & 55.72 & 32.60 & 50.00 & 52.24 & 25.46 & 59.00 \\
\hline$P_{t-3}^{*}\left[B_{t}=1\right] \geq 90 \%$ & 23.91 & 38.24 & 0.00 & 28.25 & 33.74 & 10.00 & 46.21 & 33.40 & 33.00 & 44.79 & 27.86 & 59.00 \\
\hline$P_{t-4}^{*}\left[B_{t}=1\right] \geq 60 \%$ & 26.96 & 39.89 & 0.00 & 33.75 & 36.09 & 33.33 & 53.74 & 33.27 & 50.00 & 50.39 & 26.19 & 50.00 \\
\hline$P_{t-4}^{*}\left[B_{t}=1\right] \geq 75 \%$ & 25.22 & 38.83 & 0.00 & 31.53 & 34.92 & 25.00 & 50.41 & 33.16 & 50.00 & 48.00 & 26.84 & 50.00 \\
\hline$P_{t-4}^{*}\left[B_{t}=1\right] \geq 90 \%$ & 20.44 & 36.21 & 0.00 & 25.00 & 33.51 & 0.00 & 39.56 & 36.45 & 33.00 & 40.86 & 28.05 & 40.00 \\
\hline$P_{t-5}^{*}\left[B_{t}=1\right] \geq 60 \%$ & 24.35 & 39.89 & 0.00 & 29.86 & 36.09 & 25.00 & 46.85 & 33.27 & 33.00 & 43.79 & 26.19 & 50.00 \\
\hline$P_{t-5}^{*}\left[B_{t}=1\right] \geq 75 \%$ & 21.30 & 38.83 & 0.00 & 26.53 & 34.92 & 0.00 & 45.26 & 33.16 & 33.00 & 41.70 & 26.84 & 46.00 \\
\hline$P_{t-5}^{*}\left[B_{t}=1\right] \geq 90 \%$ & 18.70 & 36.21 & 0.00 & 20.28 & 33.51 & 0.00 & 34.00 & 36.45 & 25.00 & 36.28 & 28.05 & 33.00 \\
\hline \multicolumn{13}{|c|}{ End Sample Bubbles Statistics } \\
\hline$P_{T-1}^{*}\left[B_{T}=1\right] \geq 60 \%$ & 40.00 & 49.20 & 0.00 & 60.00 & 49.40 & 100.00 & 81.54 & 39.10 & 100.00 & 77.38 & 42.09 & 100.00 \\
\hline$P_{T-1}^{*}\left[B_{T}=1\right] \geq 75 \%$ & 39.13 & 49.02 & 0.00 & 56.67 & 49.97 & 100.00 & 81.54 & 39.10 & 100.00 & 73.81 & 44.23 & 100.00 \\
\hline$P_{T-1}^{*}\left[B_{T}=1\right] \geq 90 \%$ & 36.52 & 48.36 & 0.00 & 43.33 & 49.97 & 0.00 & 66.15 & 47.69 & 100.00 & 61.91 & 48.85 & 100.00 \\
\hline$P_{T-2}^{*}\left[B_{T}=1\right] \geq 60 \%$ & 35.65 & 48.11 & 0.00 & 60.00 & 49.40 & 100.00 & 76.92 & 42.46 & 100.00 & 71.43 & 45.45 & 100.00 \\
\hline$P_{T-2}^{*}\left[B_{T}=1\right] \geq 75 \%$ & 35.65 & 48.11 & 0.00 & 53.33 & 50.31 & 100.00 & 73.85 & 44.29 & 100.00 & 65.48 & 47.83 & 100.00 \\
\hline$P_{T-2}^{*}\left[B_{T}=1\right] \geq 90 \%$ & 29.57 & 45.83 & 0.00 & 38.33 & 49.03 & 0.00 & 58.46 & 49.66 & 100.00 & 54.76 & 50.07 & 100.00 \\
\hline$P_{T-3}^{*}\left[B_{T}=1\right] \geq 60 \%$ & 33.91 & 47.55 & 0.00 & 45.00 & 50.17 & 0.00 & 69.23 & 46.51 & 100.00 & 61.91 & 48.85 & 100.00 \\
\hline$P_{T-3}^{*}\left[B_{T}=1\right] \geq 75 \%$ & 32.17 & 46.92 & 0.00 & 43.33 & 49.97 & 0.00 & 64.62 & 48.19 & 100.00 & 59.52 & 49.38 & 100.00 \\
\hline$P_{T-3}^{*}\left[B_{T}=1\right] \geq 90 \%$ & 24.35 & 43.11 & 0.00 & 35.00 & 48.10 & 0.00 & 52.31 & 50.34 & 100.00 & 47.62 & 50.24 & 0.00 \\
\hline$P_{T-4}^{*}\left[B_{T}=1\right] \geq 60 \%$ & 28.70 & 45.43 & 0.00 & 38.33 & 49.03 & 0.00 & 67.69 & 47.13 & 100.00 & 60.71 & 49.13 & 100.00 \\
\hline$P_{T-4}^{*}\left[B_{T}=1\right] \geq 75 \%$ & 26.96 & 44.57 & 0.00 & 35.00 & 48.10 & 0.00 & 63.08 & 48.64 & 100.00 & 59.52 & 49.38 & 100.00 \\
\hline$P_{T-4}^{*}\left[B_{T}=1\right] \geq 90 \%$ & 19.13 & 39.51 & 0.00 & 28.33 & 45.44 & 0.00 & 49.23 & 50.38 & 0.00 & 45.24 & 50.07 & 0.00 \\
\hline$P_{T-5}^{*}\left[B_{T}=1\right] \geq 60 \%$ & 24.35 & 45.43 & 0.00 & 33.33 & 49.03 & 0.00 & 58.46 & 47.13 & 100.00 & 53.57 & 49.13 & 100.00 \\
\hline$P_{T-5}^{*}\left[B_{T}=1\right] \geq 75 \%$ & 20.87 & 44.57 & 0.00 & 28.33 & 48.10 & 0.00 & 56.92 & 48.64 & 100.00 & 52.38 & 49.38 & 100.00 \\
\hline$P_{T-5}^{*}\left[B_{T}=1\right] \geq 90 \%$ & 17.39 & 39.51 & 0.00 & 21.67 & 45.44 & 0.00 & 43.08 & 50.38 & 0.00 & 45.24 & 50.07 & 0.00 \\
\hline \multicolumn{13}{|c|}{ All Sample Bubbles NBA Probability Distribution } \\
\hline$P_{t-1}^{*}\left[B_{t}\right]$ & 95.16 & 11.56 & 98.73 & 78.17 & 32.89 & 94.00 & 76.85 & 33.97 & 94.82 & 73.15 & 34.85 & 94.13 \\
\hline$P_{t-2}^{*}\left[B_{t}\right]$ & 90.80 & 19.49 & 97.60 & 74.05 & 34.33 & 93.00 & 71.42 & 36.73 & 93.01 & 66.72 & 37.90 & 92.36 \\
\hline$P_{t-3}^{*}\left[B_{t}\right]$ & 86.46 & 25.04 & 96.22 & 66.22 & 37.98 & 89.00 & 65.66 & 38.81 & 89.90 & 60.97 & 40.30 & 88.14 \\
\hline$P_{t-4}^{*}\left[B_{t}\right]$ & 81.46 & 29.72 & 94.41 & 58.41 & 39.76 & 79.00 & 59.22 & 40.77 & 83.78 & 55.45 & 41.39 & 77.98 \\
\hline$P_{t-5}^{*}\left[B_{t}\right]$ & 73.26 & 34.78 & 91.41 & 52.30 & 41.06 & 61.00 & 51.56 & 42.07 & 64.70 & 48.36 & 42.23 & 25.28 \\
\hline \multicolumn{13}{|c|}{ End Sample Bubbles NBA Probability Distribution } \\
\hline$P_{T-1}^{*}\left[B_{T}\right]$ & 95.09 & 9.83 & 97.92 & 79.67 & 30.44 & 93.67 & 82.56 & 27.74 & 95.42 & 77.27 & 31.14 & 95.07 \\
\hline$P_{T-2}^{*}\left[B_{T}\right]$ & 90.34 & 19.08 & 96.61 & 76.33 & 31.77 & 92.89 & 77.13 & 32.26 & 93.96 & 71.52 & 34.81 & 93.04 \\
\hline$P_{T-3}^{*}\left[B_{T}\right]$ & 85.99 & 24.80 & 95.50 & 65.88 & 38.14 & 89.68 & 70.57 & 36.55 & 92.47 & 63.97 & 39.08 & 88.46 \\
\hline$P_{T-4}^{*}\left[B_{T}\right]$ & 80.74 & 29.54 & 93.76 & 57.61 & 40.34 & 80.71 & 67.81 & 38.16 & 91.24 & 61.81 & 40.09 & 86.88 \\
\hline$P_{T-5}^{*}\left[B_{T}\right]$ & 73.16 & 34.58 & 91.24 & 50.55 & 41.95 & 55.52 & 59.85 & 41.21 & 84.53 & 55.59 & 42.06 & 80.13 \\
\hline
\end{tabular}

\subsubsection{The initial sample}

A closely related topic is the choice of the NBA's initial sample (Table 3).

This table exposes how the mechanism reacts when different sample sizes are used to calculate the first one step ahead probability $\left(\widehat{P}_{t-1}\right)$. The most important result is the positive relationship between the anticipation power and the initial sample size, which is in line with the learning dynamic formerly observed. If one considers a total sample size of $T=1000$, the NBA mechanism predicts better if using a sample of $200(20 \% \times T)$ to generate the first one step ahead probability than if using only $100(10 \% \times T)$ for the same effect. A one step ahead probability greater than $90 \%\left(P_{t-1}^{*}\left[B_{t}=1\right] \geq 90 \%\right)$ is found for $41 \%$ (all bubbles) and $57 \%$ (last bubble) of the cases in which the mechanism does not consume any initial data $(0 \% \times T)$, which compares to $54 \%$ and $61 \%$, respectively, for the case of $20 \% \times$ $T$. The NBA yields a larger percentage of valid predictions when $40 \% \times T$ points are consumed, but the anticipation power as a whole is much weaker than the other cases. 
Table 3

Monte Carlo simulation - the initial sample.

\begin{tabular}{|c|c|c|c|c|c|c|c|c|c|}
\hline \multirow{2}{*}{$\frac{\text { Parameters }}{\text { Statistics }}$} & \multicolumn{3}{|c|}{$0 \% \times T$} & \multicolumn{3}{|c|}{$20 \% \times T$} & \multicolumn{3}{|c|}{$40 \% \times T$} \\
\hline & $\bar{X}$ & $\Sigma X$ & $\operatorname{Med}(X)$ & $\bar{X}$ & $\Sigma X$ & $\operatorname{Med}(X)$ & $\bar{X}$ & $\Sigma X$ & $\operatorname{Med}(X)$ \\
\hline$P^{*} / T$ & 61.15 & 19.51 & 65.00 & 84.95 & 16.42 & 91.63 & 89.53 & 13.65 & 95.00 \\
\hline$\#\left(B_{1, \ldots, T}\right)$ & 6.14 & 2.04 & 6.00 & 4.98 & 1.79 & 5.00 & 4.50 & 1.45 & 4.50 \\
\hline$\# a\left(P_{t-1}^{*}\left[B_{t}\right] \geq 60 \%\right)$ & 2.98 & 1.36 & 3.00 & 3.23 & 1.31 & 3.00 & 2.93 & 0.92 & 3.00 \\
\hline$\# e\left(P_{T-1}^{*}\left[B_{T}\right] \geq 60 \%\right)$ & 0.73 & 0.45 & 1.00 & 0.77 & 0.42 & 1.00 & 0.50 & 0.52 & 0.50 \\
\hline \multicolumn{10}{|c|}{ All Sample Bubbles Statistics } \\
\hline$P_{t-1}^{*}\left[B_{t}=1\right] \geq 60 \%$ & 51.01 & 22.28 & 50.00 & 66.44 & 23.08 & 66.00 & 68.55 & 21.75 & 69.05 \\
\hline$P_{t-1}^{*}\left[B_{t}=1\right] \geq 75 \%$ & 49.93 & 23.18 & 50.00 & 62.88 & 25.05 & 64.00 & 63.32 & 28.70 & 69.04 \\
\hline$P_{t-1}^{*}\left[B_{t}=1\right] \geq 90 \%$ & 41.12 & 25.81 & 37.50 & 54.83 & 26.76 & 57.00 & 48.96 & 31.89 & 50.00 \\
\hline$P_{t-2}^{*}\left[B_{t}=1\right] \geq 60 \%$ & 47.95 & 22.99 & 50.00 & 59.95 & 24.98 & 60.00 & 62.53 & 22.22 & 63.33 \\
\hline$P_{t-2}^{*}\left[B_{t}=1\right] \geq 75 \%$ & 46.27 & 24.39 & 50.00 & 56.60 & 26.17 & 58.00 & 56.11 & 28.87 & 58.57 \\
\hline$P_{t-2}^{*}\left[B_{t}=1\right] \geq 90 \%$ & 35.70 & 26.01 & 33.33 & 49.07 & 27.68 & 50.00 & 36.33 & 29.40 & 33.33 \\
\hline$P_{t-3}^{*}\left[B_{t}=1\right] \geq 60 \%$ & 44.01 & 23.42 & 42.86 & 55.11 & 25.85 & 60.00 & 49.56 & 28.17 & 50.00 \\
\hline$P_{t-3}^{*}\left[B_{t}=1\right] \geq 75 \%$ & 41.60 & 24.20 & 38.75 & 52.24 & 25.46 & 59.00 & 46.94 & 31.16 & 50.00 \\
\hline$P_{t-3}^{*}\left[B_{t}=1\right] \geq 90 \%$ & 31.53 & 24.58 & 25.00 & 44.79 & 27.86 & 59.00 & 39.37 & 28.67 & 26.79 \\
\hline$P_{t-4}^{*}\left[B_{t}=1\right] \geq 60 \%$ & 39.32 & 24.38 & 35.42 & 50.39 & 26.19 & 50.00 & 44.56 & 32.16 & 50.00 \\
\hline$P_{t-4}^{*}\left[B_{t}=1\right] \geq 75 \%$ & 36.43 & 25.16 & 33.33 & 48.00 & 26.84 & 50.00 & 42.77 & 32.53 & 45.00 \\
\hline$P_{t-4}^{*}\left[B_{t}=1\right] \geq 90 \%$ & 28.34 & 25.37 & 20.00 & 40.86 & 28.05 & 40.00 & 23.76 & 27.63 & 18.00 \\
\hline$P_{t-5}^{*}\left[B_{t}=1\right] \geq 60 \%$ & 34.80 & 24.38 & 30.95 & 43.79 & 26.19 & 50.00 & 38.18 & 32.16 & 41.00 \\
\hline$P_{t-5}^{*}\left[B_{t}=1\right] \geq 75 \%$ & 32.29 & 25.16 & 25.00 & 41.70 & 26.84 & 46.00 & 36.99 & 32.53 & 41.00 \\
\hline$P_{t-5}^{*}\left[B_{t}=1\right] \geq 90 \%$ & 24.31 & 25.37 & 16.67 & 36.28 & 28.05 & 33.00 & 16.97 & 27.63 & 15.00 \\
\hline \multicolumn{10}{|c|}{ End Sample Bubbles Statistics } \\
\hline$P_{T-1}^{*}\left[B_{T}=1\right] \geq 60 \%$ & 72.73 & 44.79 & 100.00 & 77.38 & 42.09 & 100.00 & 50.00 & 51.89 & 50.00 \\
\hline$P_{T-1}^{*}\left[B_{T}=1\right] \geq 75 \%$ & 68.18 & 46.84 & 100.00 & 73.81 & 44.23 & 100.00 & 50.00 & 51.89 & 50.00 \\
\hline$P_{T-1}^{*}\left[B_{T}=1\right] \geq 90 \%$ & 56.82 & 49.82 & 100.00 & 61.91 & 48.85 & 100.00 & 42.86 & 51.36 & 0.00 \\
\hline$P_{T-2}^{*}\left[B_{T}=1\right] \geq 60 \%$ & 65.91 & 47.67 & 100.00 & 71.43 & 45.45 & 100.00 & 50.00 & 51.89 & 50.00 \\
\hline$P_{T-2}^{*}\left[B_{T}=1\right] \geq 75 \%$ & 62.50 & 48.69 & 100.00 & 65.48 & 47.83 & 100.00 & 50.00 & 51.89 & 50.00 \\
\hline$P_{T-2}^{*}\left[B_{T}=1\right] \geq 90 \%$ & 47.73 & 50.24 & 0.00 & 54.76 & 50.07 & 100.00 & 35.71 & 49.73 & 0.00 \\
\hline$P_{T-3}^{*}\left[B_{T}=1\right] \geq 60 \%$ & 59.09 & 49.45 & 100.00 & 61.91 & 48.85 & 100.00 & 28.57 & 46.88 & 0.00 \\
\hline$P_{T-3}^{*}\left[B_{T}=1\right] \geq 75 \%$ & 56.82 & 49.82 & 100.00 & 59.52 & 49.38 & 100.00 & 28.57 & 46.88 & 0.00 \\
\hline$P_{T-3}^{*}\left[B_{T}=1\right] \geq 90 \%$ & 40.91 & 49.45 & 0.00 & 47.62 & 50.24 & 0.00 & 28.57 & 46.88 & 0.00 \\
\hline$P_{T-4}^{*}\left[B_{T}=1\right] \geq 60 \%$ & 52.27 & 50.24 & 100.00 & 60.71 & 49.13 & 100.00 & 28.57 & 46.88 & 0.00 \\
\hline$P_{T-4}^{*}\left[B_{T}=1\right] \geq 75 \%$ & 50.00 & 50.29 & 50.00 & 59.52 & 49.38 & 100.00 & 28.57 & 46.88 & 0.00 \\
\hline$P_{T-4}^{*}\left[B_{T}=1\right] \geq 90 \%$ & 34.09 & 47.67 & 0.00 & 45.24 & 50.07 & 0.00 & 21.43 & 42.58 & 0.00 \\
\hline$P_{T-5}^{*}\left[B_{T}=1\right] \geq 60 \%$ & 44.32 & 50.24 & 0.00 & 53.57 & 49.13 & 100.00 & 28.57 & 46.88 & 0.00 \\
\hline$P_{T-5}^{*}\left[B_{T}=1\right] \geq 75 \%$ & 43.18 & 50.29 & 0.00 & 52.38 & 49.38 & 100.00 & 28.57 & 46.88 & 0.00 \\
\hline$P_{T-5}^{*}\left[B_{T}=1\right] \geq 90 \%$ & 30.68 & 47.67 & 0.00 & 45.24 & 50.07 & 0.00 & 21.43 & 42.58 & 0.00 \\
\hline \multicolumn{10}{|c|}{ All Sample Bubbles NBA Probability Distribution } \\
\hline$P_{t-1}^{*}\left[B_{t}\right]$ & 68.04 & 39.26 & 92.00 & 73.15 & 34.85 & 94.13 & 64.99 & 38.47 & 88.28 \\
\hline$P_{t-2}^{*}\left[B_{t}\right]$ & 63.58 & 40.69 & 88.00 & 66.72 & 37.90 & 92.36 & 58.77 & 39.68 & 82.87 \\
\hline$P_{t-3}^{*}\left[B_{t}\right]$ & 57.76 & 41.95 & 82.00 & 60.97 & 40.30 & 88.14 & 49.56 & 40.83 & 58.94 \\
\hline$P_{t-4}^{*}\left[B_{t}\right]$ & 50.79 & 42.69 & 52.00 & 55.45 & 41.39 & 77.98 & 42.33 & 41.89 & 11.43 \\
\hline$P_{t-5}^{*}\left[B_{t}\right]$ & 44.81 & 43.22 & 16.00 & 48.36 & 42.23 & 25.28 & 37.24 & 40.97 & 9.11 \\
\hline \multicolumn{10}{|c|}{ End Sample Bubbles NBA Probability Distribution } \\
\hline$P_{T-1}^{*}\left[B_{T}\right]$ & 69.56 & 36.88 & 92.48 & 77.27 & 31.14 & 95.07 & 52.50 & 43.63 & 49.05 \\
\hline$P_{T-2}^{*}\left[B_{T}\right]$ & 64.87 & 39.34 & 88.48 & 71.52 & 34.81 & 93.04 & 51.10 & 43.68 & 46.47 \\
\hline$P_{T-3}^{*}\left[B_{T}\right]$ & 57.89 & 41.56 & 83.18 & 63.97 & 39.08 & 88.46 & 35.18 & 40.89 & 13.32 \\
\hline$P_{T-4}^{*}\left[B_{T}\right]$ & 51.56 & 42.50 & 74.82 & 61.81 & 40.09 & 86.88 & 32.51 & 41.48 & 18.17 \\
\hline$P_{T-5}^{*}\left[B_{T}\right]$ & 44.53 & 42.98 & 17.23 & 55.59 & 42.06 & 80.13 & 31.40 & 41.71 & 8.31 \\
\hline
\end{tabular}

\subsubsection{Constant gains}

The importance of how the abnormal returns are estimated is absolutely crucial for the mechanism's effectiveness. As a consequence, it is important to observe how the NBA mechanism responds to different constant gains, $\gamma$. The results are in Table 4 .

The results considering $\gamma=0.1$ and $\gamma=0.2$ are quite similar. However, we see some sensitivity of the prediction power to the value of this parameter, especially for the highest value considered of $\gamma=0.4$. In this setting, the NBA provides a one step ahead probability greater than $90 \%\left(P_{t-1}^{*}\left[B_{t}=1\right] \geq 90 \%\right)$ for approximately $47 \%$ of the cases taking all generated bubbles and $43 \%$ looking only at the last bubble, whereas for the standard value of $\gamma=0.2$ these become $55 \%$ and $62 \%$, respectively. This is not a surprising result because this parameter controls for how the investor perceives structural changes in his/her learning rule. If $\gamma$ is too high, then it tends to constantly overestimate changes, which ultimately diminishes the predicting power. 
Table 4

Monte Carlo simulation - constant gains.

\begin{tabular}{|c|c|c|c|c|c|c|c|c|c|}
\hline \multirow{2}{*}{$\frac{\text { Parameters }}{\text { Statistics }}$} & \multicolumn{3}{|c|}{$\gamma=0.1$} & \multicolumn{3}{|c|}{$\gamma=0.2$} & \multicolumn{3}{|c|}{$\gamma=0.4$} \\
\hline & $\bar{X}$ & $\Sigma X$ & $\operatorname{Med}(X)$ & $\bar{X}$ & $\Sigma X$ & $\operatorname{Med}(X)$ & $\bar{X}$ & $\Sigma X$ & $\operatorname{Med}(X)$ \\
\hline$P^{*} / T$ & 68.04 & 30.11 & 73.00 & 84.94 & 16.42 & 91.63 & 85.65 & 16.23 & 99.20 \\
\hline$\#\left(B_{1}, \ldots, T\right)$ & 4.086 & 1.48 & 4.00 & 4.97 & 1.79 & 5.00 & 5.09 & 1.86 & 5.00 \\
\hline$\# a\left(P_{t-1}^{*}\left[B_{t}\right] \geq 60 \%\right)$ & 2.61 & 1.25 & 3.00 & 3.22 & 1.31 & 3.00 & 3.02 & 1.31 & 3.00 \\
\hline$\# e\left(P_{T-1}^{*}\left[B_{T}\right] \geq 60 \%\right)$ & 0.76 & 0.42 & 1.00 & 0.77 & 0.42 & 1.00 & 0.62 & 0.48 & 1.00 \\
\hline \multicolumn{10}{|c|}{ All Sample Bubbles Statistics } \\
\hline$P_{t-1}^{*}\left[B_{t}=1\right] \geq 60 \%$ & 67.75 & 28.65 & 66.00 & 66.44 & 23.08 & 66.00 & 60.98 & 22.71 & 60.00 \\
\hline$P_{t-1}^{*}\left[B_{t}=1\right] \geq 75 \%$ & 64.97 & 30.54 & 66.00 & 62.88 & 25.05 & 64.00 & 56.14 & 22.59 & 60.00 \\
\hline$P_{t-1}^{*}\left[B_{t}=1\right] \geq 90 \%$ & 59.08 & 30.73 & 60.00 & 54.83 & 26.75 & 57.00 & 46.46 & 25.03 & 50.00 \\
\hline$P_{t-2}^{*}\left[B_{t}=1\right] \geq 60 \%$ & 61.44 & 29.82 & 66.00 & 59.95 & 24.97 & 60.00 & 55.11 & 25.46 & 50.00 \\
\hline$P_{t-2}^{*}\left[B_{t}=1\right] \geq 75 \%$ & 59.49 & 30.38 & 60.00 & 56.60 & 26.17 & 58.00 & 52.09 & 24.36 & 50.00 \\
\hline$P_{t-2}^{*}\left[B_{t}=1\right] \geq 90 \%$ & 53.14 & 31.92 & 50.00 & 49.06 & 27.67 & 50.00 & 43.50 & 27.24 & 50.00 \\
\hline$P_{t-3}^{*}\left[B_{t}=1\right] \geq 60 \%$ & 52.90 & 31.62 & 50.00 & 55.11 & 25.85 & 60.00 & 52.24 & 24.99 & 50.00 \\
\hline$P_{t-3}^{*}\left[B_{t}=1\right] \geq 75 \%$ & 51.67 & 31.71 & 50.00 & 52.24 & 25.45 & 59.00 & 48.55 & 25.35 & 50.00 \\
\hline$P_{t-3}^{*}\left[B_{t}=1\right] \geq 90 \%$ & 45.46 & 31.53 & 50.00 & 44.78 & 27.86 & 59.00 & 42.10 & 26.64 & 40.00 \\
\hline$P_{t-4}^{*}\left[B_{t}=1\right] \geq 60 \%$ & 48.57 & 31.51 & 50.00 & 50.39 & 26.19 & 50.00 & 47.40 & 26.22 & 42.85 \\
\hline$P_{t-4}^{*}\left[B_{t}=1\right] \geq 75 \%$ & 46.20 & 30.99 & 40.00 & 48.00 & 26.84 & 50.00 & 43.20 & 24.70 & 40.00 \\
\hline$P_{t-4}^{*}\left[B_{t}=1\right] \geq 90 \%$ & 40.12 & 30.96 & 33.30 & 40.86 & 28.04 & 40.00 & 38.84 & 25.44 & 33.33 \\
\hline$P_{t-5}^{*}\left[B_{t}=1\right] \geq 60 \%$ & 44.85 & 31.51 & 40.00 & 43.78 & 26.19 & 50.00 & 40.51 & 26.22 & 33.33 \\
\hline$P_{t-5}^{*}\left[B_{t}=1\right] \geq 75 \%$ & 42.38 & 30.99 & 33.30 & 41.70 & 26.84 & 46.00 & 37.86 & 24.70 & 33.33 \\
\hline$P_{t-5}^{*}\left[B_{t}=1\right] \geq 90 \%$ & 37.18 & 30.96 & 33.30 & 36.28 & 28.04 & 33.00 & 32.26 & 25.44 & 28.57 \\
\hline \multicolumn{10}{|c|}{ End Sample Bubbles Statistics } \\
\hline$P_{T-1}^{*}\left[B_{T}=1\right] \geq 60 \%$ & 76.54 & 42.63 & 100.00 & 77.38 & 42.08 & 100.00 & 62.96 & 48.59 & 100.00 \\
\hline$P_{T-1}^{*}\left[B_{T}=1\right] \geq 75 \%$ & 74.07 & 44.09 & 100.00 & 73.81 & 44.23 & 100.00 & 58.02 & 49.65 & 100.00 \\
\hline$P_{T-1}^{*}\left[B_{T}=1\right] \geq 90 \%$ & 67.90 & 46.97 & 100.00 & 61.90 & 48.85 & 100.00 & 43.21 & 49.84 & 0.00 \\
\hline$P_{T-2}^{*}\left[B_{T}=1\right] \geq 60 \%$ & 70.37 & 45.94 & 100.00 & 71.42 & 45.44 & 100.00 & 55.55 & 50.00 & 100.00 \\
\hline$P_{T-2}^{*}\left[B_{T}=1\right] \geq 75 \%$ & 69.13 & 46.48 & 100.00 & 65.47 & 47.83 & 100.00 & 54.32 & 50.12 & 100.00 \\
\hline$P_{T-2}^{*}\left[B_{T}=1\right] \geq 90 \%$ & 59.25 & 49.44 & 100.00 & 54.76 & 50.07 & 100.00 & 40.74 & 49.44 & 0.00 \\
\hline$P_{T-3}^{*}\left[B_{T}=1\right] \geq 60 \%$ & 59.25 & 49.44 & 100.00 & 61.90 & 48.85 & 100.00 & 50.61 & 58.30 & 100.00 \\
\hline$P_{T-3}^{*}\left[B_{T}=1\right] \geq 75 \%$ & 58.02 & 49.65 & 100.00 & 59.52 & 49.37 & 100.00 & 48.14 & 50.27 & 0.00 \\
\hline$P_{T-3}^{*}\left[B_{T}=1\right] \geq 90 \%$ & 51.85 & 50.27 & 100.00 & 47.61 & 50.24 & 0.00 & 40.74 & 49.44 & 0.00 \\
\hline$P_{T-4}^{*}\left[B_{T}=1\right] \geq 60 \%$ & 55.55 & 50.00 & 100.00 & 60.71 & 49.13 & 100.00 & 45.67 & 50.12 & 0.00 \\
\hline$P_{T-4}^{*}\left[B_{T}=1\right] \geq 75 \%$ & 53.08 & 50.21 & 100.00 & 59.52 & 49.37 & 100.00 & 43.21 & 49.84 & 0.00 \\
\hline$P_{T-4}^{*}\left[B_{T}=1\right] \geq 90 \%$ & 45.67 & 50.12 & 0.00 & 45.23 & 50.07 & 0.00 & 38.27 & 48.90 & 0.00 \\
\hline$P_{T-5}^{*}\left[B_{T}=1\right] \geq 60 \%$ & 50.61 & 50.00 & 100.00 & 53.57 & 49.13 & 100.00 & 39.50 & 50.12 & 0.00 \\
\hline$P_{T-5}^{*}\left[B_{T}=1\right] \geq 75 \%$ & 49.38 & 50.21 & 0.00 & 52.38 & 49.37 & 100.00 & 37.03 & 49.84 & 0.00 \\
\hline$P_{T-5}^{*}\left[B_{T}=1\right] \geq 90 \%$ & 44.44 & 50.12 & 0.00 & 45.23 & 50.07 & 0.00 & 29.63 & 48.90 & 0.00 \\
\hline \multicolumn{10}{|c|}{ All Sample Bubbles NBA Probability Distribution } \\
\hline$P_{t-1}^{*}\left[B_{t}\right]$ & 74.71 & 36.32 & 95.41 & 73.15 & 34.85 & 94.13 & 67.00 & 36.46 & 89.75 \\
\hline$P_{t-2}^{*}\left[B_{t}\right]$ & 68.19 & 39.49 & 93.50 & 66.72 & 37.89 & 92.36 & 61.64 & 38.15 & 84.89 \\
\hline$P_{t-3}^{*}\left[B_{t}\right]$ & 60.47 & 42.18 & 90.56 & 60.96 & 40.29 & 88.13 & 57.15 & 39.59 & 72.63 \\
\hline$P_{t-4}^{*}\left[B_{t}\right]$ & 54.54 & 43.31 & 80.28 & 55.44 & 41.39 & 77.97 & 52.01 & 40.47 & 36.23 \\
\hline$P_{t-5}^{*}\left[B_{t}\right]$ & 48.90 & 43.98 & 27.17 & 48.36 & 42.22 & 25.28 & 44.37 & 40.64 & 20.20 \\
\hline \multicolumn{10}{|c|}{ End Sample Bubbles NBA Probability Distribution } \\
\hline$P_{T-1}^{*}\left[B_{T}\right]$ & 77.20 & 34.71 & 95.45 & 77.26 & 31.13 & 95.07 & 66.25 & 34.84 & 84.48 \\
\hline$P_{T-2}^{*}\left[B_{T}\right]$ & 71.04 & 38.38 & 94.15 & 71.51 & 34.80 & 93.04 & 60.47 & 37.45 & 80.87 \\
\hline$P_{T-3}^{*}\left[B_{T}\right]$ & 61.62 & 42.16 & 91.44 & 63.96 & 39.07 & 88.46 & 55.97 & 39.21 & 62.63 \\
\hline$P_{T-4}^{*}\left[B_{T}\right]$ & 57.00 & 43.67 & 88.56 & 61.81 & 40.09 & 86.87 & 51.51 & 40.09 & 45.77 \\
\hline$P_{T-5}^{*}\left[B_{T}\right]$ & 52.11 & 44.95 & 84.67 & 55.58 & 42.06 & 80.13 & 44.20 & 40.90 & 21.70 \\
\hline
\end{tabular}

\subsubsection{Asset pricing contribution}

One of the most important results in this section is given in Table 5 because it emphasizes how important the asset pricing model component is for a robust anticipation of the occurrence of a bubble. To the left we have the results after estimating the dynamic probit model without the equilibrium model, $\beta_{2}=0$, and to the right, with the full set of covariates.

At a first glance both settings look very similar in terms of results. However, an in-depth analysis reveals a very interesting pattern. Without the asset pricing equilibrium model, the NBA mechanism can indicate a one step ahead probability greater than $90 \%$ for only $17 \%$ of the cases considering all bubbles and $10 \%$ by looking only at the last bubble. In fact, this means that the mechanism loses its learning ability by delivering poorer results in the last portion of the sample. When considering a five steps ahead probability, the NBA without fundamentals cannot predict more than $5 \%$ of the end sample bubbles, whereas for the same threshold but with fundamentals it can predict $45 \%$ of the end sample bubbles, which is five times more! The main conclusion is: The NBA presents a higher prediction power when the asset pricing model term is included in its specification. This result is very important in this literature. 
Table 5

Monte Carlo simulation - asset pricing contribution.

\begin{tabular}{|c|c|c|c|c|c|c|}
\hline \multirow{2}{*}{$\begin{array}{l}\text { Parameters } \\
\text { Statistics }\end{array}$} & \multicolumn{3}{|c|}{ No Equilibrium Model $\left(\beta_{2}=0\right)$} & \multicolumn{3}{|c|}{ Full NBA } \\
\hline & $\bar{X}$ & $\Sigma X$ & $\operatorname{Med}(X)$ & $\bar{X}$ & $\Sigma X$ & $\operatorname{Med}(X)$ \\
\hline$P^{*} / T$ & 97.76 & 3.12 & 98.00 & 84.94 & 16.42 & 91.63 \\
\hline$\#\left(B_{1}, \ldots, T\right)$ & 5.27 & 1.74 & 5.00 & 4.97 & 1.79 & 5.00 \\
\hline$\# a\left(P_{t-1}^{*}\left[B_{t}\right] \geq 60 \%\right)$ & 3.30 & 1.14 & 3.00 & 3.22 & 1.31 & 3.00 \\
\hline$\# e\left(P_{T-1}^{*}\left[B_{T}\right] \geq 60 \%\right)$ & 0.72 & 0.45 & 1.00 & 0.77 & 0.42 & 1.00 \\
\hline \multicolumn{7}{|c|}{ All Sample Bubbles Statistics } \\
\hline$P_{t-1}^{*}\left[B_{t}=1\right] \geq 60 \%$ & 66.82 & 21.95 & 66.66 & 66.44 & 23.08 & 66.00 \\
\hline$P_{t-1}^{*}\left[B_{t}=1\right] \geq 75 \%$ & 64.69 & 23.88 & 66.66 & 62.88 & 25.05 & 64.00 \\
\hline$P_{t-1}^{*}\left[B_{t}=1\right] \geq 90 \%$ & 17.00 & 27.23 & 0.00 & 54.83 & 26.75 & 57.00 \\
\hline$P_{t-2}^{*}\left[B_{t}=1\right] \geq 60 \%$ & 62.40 & 22.42 & 61.25 & 59.95 & 24.97 & 60.00 \\
\hline$P_{t-2}^{*}\left[B_{t}=1\right] \geq 75 \%$ & 59.68 & 24.07 & 60.00 & 56.60 & 26.17 & 58.00 \\
\hline$P_{t-2}^{*}\left[B_{t}=1\right] \geq 90 \%$ & 14.34 & 24.96 & 0.00 & 49.06 & 27.67 & 50.00 \\
\hline$P_{t-3}^{*}\left[B_{t}=1\right] \geq 60 \%$ & 57.25 & 25.09 & 52.77 & 55.11 & 25.85 & 60.00 \\
\hline$P_{t-3}^{*}\left[B_{t}=1\right] \geq 75 \%$ & 54.79 & 27.04 & 50.00 & 52.24 & 25.45 & 59.00 \\
\hline$P_{t-3}^{*}\left[B_{t}=1\right] \geq 90 \%$ & 13.23 & 24.82 & 0.00 & 44.78 & 27.86 & 59.00 \\
\hline$P_{t-4}^{*}\left[B_{t}=1\right] \geq 60 \%$ & 50.63 & 24.72 & 50.00 & 50.39 & 26.19 & 50.00 \\
\hline$P_{t-4}^{*}\left[B_{t}=1\right] \geq 75 \%$ & 46.97 & 26.62 & 50.00 & 48.00 & 26.84 & 50.00 \\
\hline$P_{t-4}^{*}\left[B_{t}=1\right] \geq 90 \%$ & 11.27 & 23.05 & 0.00 & 40.86 & 28.04 & 40.00 \\
\hline$P_{t-5}^{*}\left[B_{t}=1\right] \geq 60 \%$ & 43.75 & 24.72 & 40.00 & 43.78 & 26.19 & 50.00 \\
\hline$P_{t-5}^{*}\left[B_{t}=1\right] \geq 75 \%$ & 41.14 & 26.62 & 40.00 & 41.70 & 26.84 & 46.00 \\
\hline$P_{t-5}^{*}\left[B_{t}=1\right] \geq 90 \%$ & 9.97 & 23.05 & 0.00 & 36.28 & 28.04 & 33.00 \\
\hline \multicolumn{7}{|c|}{ End Sample Bubbles Statistics } \\
\hline$P_{T-1}^{*}\left[B_{T}=1\right] \geq 60 \%$ & 72.36 & 45.01 & 100.00 & 77.38 & 42.08 & 100.00 \\
\hline$P_{T-1}^{*}\left[B_{T}=1\right] \geq 75 \%$ & 71.05 & 45.65 & 100.00 & 73.81 & 44.23 & 100.00 \\
\hline$P_{T-1}^{*}\left[B_{T}=1\right] \geq 90 \%$ & 10.52 & 30.89 & 0.00 & 61.90 & 48.85 & 100.00 \\
\hline$P_{T-2}^{*}\left[B_{T}=1\right] \geq 60 \%$ & 64.47 & 48.17 & 100.00 & 71.42 & 45.44 & 100.00 \\
\hline$P_{T-2}^{*}\left[B_{T}=1\right] \geq 75 \%$ & 63.15 & 48.55 & 100.00 & 65.47 & 47.83 & 100.00 \\
\hline$P_{T-2}^{*}\left[B_{T}=1\right] \geq 90 \%$ & 10.52 & 30.89 & 0.00 & 54.76 & 50.07 & 100.00 \\
\hline$P_{T-3}^{*}\left[B_{T}=1\right] \geq 60 \%$ & 59.21 & 49.47 & 100.00 & 61.90 & 48.85 & 100.00 \\
\hline$P_{T-3}^{*}\left[B_{T}=1\right] \geq 75 \%$ & 57.89 & 49.70 & 100.00 & 59.52 & 49.37 & 100.00 \\
\hline$P_{T-3}^{*}\left[B_{T}=1\right] \geq 90 \%$ & 7.89 & 27.14 & 0.00 & 47.61 & 50.24 & 0.00 \\
\hline$P_{T-4}^{*}\left[B_{T}=1\right] \geq 60 \%$ & 50.00 & 50.33 & 50.00 & 60.71 & 49.13 & 100.00 \\
\hline$P_{T-4}^{*}\left[B_{T}=1\right] \geq 75 \%$ & 48.68 & 50.31 & 0.00 & 59.52 & 49.37 & 100.00 \\
\hline$P_{T-4}^{*}\left[B_{T}=1\right] \geq 90 \%$ & 5.26 & 22.47 & 0.00 & 45.23 & 50.07 & 0.00 \\
\hline$P_{T-5}^{*}\left[B_{T}=1\right] \geq 60 \%$ & 42.10 & 50.33 & 0.00 & 53.57 & 49.13 & 100.00 \\
\hline$P_{T-5}^{*}\left[B_{T}=1\right] \geq 75 \%$ & 40.78 & 50.31 & 0.00 & 52.38 & 49.37 & 100.00 \\
\hline$P_{T-5}^{*}\left[B_{T}=1\right] \geq 90 \%$ & 5.26 & 22.47 & 0.00 & 45.23 & 50.07 & 0.00 \\
\hline \multicolumn{7}{|c|}{ All Sample Bubbles NBA Probability Distribution } \\
\hline$P_{t-1}^{*}\left[B_{t}\right]$ & 56.22 & 40.95 & 83.33 & 73.15 & 34.85 & 94.13 \\
\hline$P_{t-2}^{*}\left[B_{t}\right]$ & 51.97 & 41.84 & 80.95 & 66.72 & 37.89 & 92.36 \\
\hline$P_{t-3}^{*}\left[B_{t}\right]$ & 46.49 & 42.69 & 76.92 & 60.96 & 40.29 & 88.13 \\
\hline$P_{t-4}^{*}\left[B_{t}\right]$ & 40.77 & 42.55 & 1.26 & 55.44 & 41.39 & 77.97 \\
\hline$P_{t-5}^{*}\left[B_{t}\right]$ & 34.67 & 41.61 & 1.09 & 48.36 & 42.22 & 25.28 \\
\hline \multicolumn{7}{|c|}{ End Sample Bubbles NBA Probability Distribution } \\
\hline$P_{T-1}^{*}\left[B_{T}\right]$ & 61.98 & 38.20 & 83.82 & 77.26 & 31.13 & 95.07 \\
\hline$P_{T-2}^{*}\left[B_{T}\right]$ & 55.27 & 40.80 & 82.64 & 71.51 & 34.80 & 93.04 \\
\hline$P_{T-3}^{*}\left[B_{T}\right]$ & 50.82 & 41.87 & 80.27 & 63.96 & 39.07 & 88.46 \\
\hline$P_{T-4}^{*}\left[B_{T}\right]$ & 43.16 & 42.70 & 37.04 & 61.81 & 40.09 & 86.87 \\
\hline$P_{T-5}^{*}\left[B_{T}\right]$ & 36.43 & 42.12 & 1.11 & 55.58 & 42.06 & 80.13 \\
\hline
\end{tabular}

\subsubsection{Bubble trigger, restarting, and scale}

As a final consideration, it is important to study the NBA's predictive power covering different types of bubbles. Recall that Evans' bubble generating process depends upon $\alpha>0, \delta>0$, and $\pi \in[0,1]$. The constant $\alpha$ controls for the length of time before a bubble collapses, $\delta$ determines the frequency at which the bubbles erupt, and $\pi$ is the probability of collapsing.

In Table 6 we see what happens when the average duration of exuberance is modified.

First, there is a sharp decrease in the number of valid probabilities once the average duration of each bubble gets large ( $\alpha=10)$. It is not an intuitive result. This setting presents the highest percentage of last bubble predictability, for a $90 \%$ threshold and five steps ahead probability, with exactly $65 \%$ on average, representing 30\% more than the standard duration $(\alpha=1)$ and $70 \%$ more than the lowest duration setting ( $\alpha=0.1$ ). In line with this result, the NBA probability distribution has a mean value of $90 \%$ and very small standard deviations when compared to the low duration settings. This value also tends to increase as the number of steps ahead rises. Therefore, 
Table 6

Monte Carlo simulation - bubble trigger.

\begin{tabular}{|c|c|c|c|c|c|c|c|c|c|}
\hline \multirow{2}{*}{$\frac{\text { Parameters }}{\text { Statistics }}$} & \multicolumn{3}{|c|}{$\alpha=0.1$} & \multicolumn{3}{|l|}{$\alpha=1$} & \multicolumn{3}{|l|}{$\alpha=10$} \\
\hline & $\bar{X}$ & $\Sigma X$ & $\operatorname{Med}(X)$ & $\bar{X}$ & $\Sigma X$ & $\operatorname{Med}(X)$ & $\bar{X}$ & $\Sigma X$ & $\operatorname{Med}(X)$ \\
\hline$P^{*} / T$ & 80.28 & 20.33 & 87.00 & 84.95 & 16.42 & 91.63 & 65.93 & 31.68 & 76.00 \\
\hline$\#\left(B_{1, \ldots, T}\right)$ & 5.47 & 2.31 & 6.00 & 4.98 & 1.79 & 5.00 & 5.49 & 2.07 & 6.00 \\
\hline$\# a\left(P_{t-1}^{*}\left[B_{t}\right] \geq 60 \%\right)$ & 3.02 & 1.46 & 3.00 & 3.23 & 1.31 & 3.00 & 3.28 & 2.39 & 3.00 \\
\hline$\# e\left(P_{T-1}^{*}\left[B_{T}\right] \geq 60 \%\right)$ & 0.54 & 0.50 & 1.00 & 0.77 & 0.42 & 1.00 & 0.75 & 0.44 & 1.00 \\
\hline \multicolumn{10}{|c|}{ All Sample Bubbles Statistics } \\
\hline$P_{t-1}^{*}\left[B_{t}=1\right] \geq 60 \%$ & 60.77 & 28.20 & 60.00 & 66.44 & 23.08 & 66.00 & 55.75 & 34.88 & 60.00 \\
\hline$P_{t-1}^{*}\left[B_{t}=1\right] \geq 75 \%$ & 58.14 & 28.42 & 56.35 & 62.88 & 25.05 & 64.00 & 55.75 & 34.88 & 60.00 \\
\hline$P_{t-1}^{*}\left[B_{t}=1\right] \geq 90 \%$ & 46.83 & 30.93 & 42.85 & 54.83 & 26.76 & 57.00 & 34.73 & 25.54 & 35.42 \\
\hline$P_{t-2}^{*}\left[B_{t}=1\right] \geq 60 \%$ & 54.82 & 29.77 & 50.00 & 59.95 & 24.98 & 60.00 & 56.74 & 35.42 & 64.58 \\
\hline$P_{t-2}^{*}\left[B_{t}=1\right] \geq 75 \%$ & 51.71 & 30.60 & 50.00 & 56.60 & 26.17 & 58.00 & 56.74 & 35.42 & 64.58 \\
\hline$P_{t-2}^{*}\left[B_{t}=1\right] \geq 90 \%$ & 40.88 & 30.74 & 33.00 & 49.07 & 27.68 & 50.00 & 40.32 & 27.79 & 46.43 \\
\hline$P_{t-3}^{*}\left[B_{t}=1\right] \geq 60 \%$ & 50.77 & 30.46 & 44.00 & 55.11 & 25.85 & 60.00 & 57.73 & 35.03 & 66.66 \\
\hline$P_{t-3}^{*}\left[B_{t}=1\right] \geq 75 \%$ & 47.42 & 31.18 & 40.00 & 52.24 & 25.46 & 59.00 & 57.73 & 35.03 & 66.66 \\
\hline$P_{t-3}^{*}\left[B_{t}=1\right] \geq 90 \%$ & 38.41 & 30.67 & 33.00 & 44.79 & 27.86 & 59.00 & 42.59 & 29.04 & 50.00 \\
\hline$P_{t-4}^{*}\left[B_{t}=1\right] \geq 60 \%$ & 45.47 & 31.57 & 34.00 & 50.39 & 26.19 & 50.00 & 59.09 & 35.92 & 66.66 \\
\hline$P_{t-4}^{*}\left[B_{t}=1\right] \geq 75 \%$ & 43.73 & 31.97 & 33.00 & 48.00 & 26.84 & 50.00 & 58.59 & 35.70 & 66.66 \\
\hline$P_{t-4}^{*}\left[B_{t}=1\right] \geq 90 \%$ & 34.68 & 30.55 & 25.00 & 40.86 & 28.05 & 40.00 & 45.72 & 30.71 & 50.00 \\
\hline$P_{t-5}^{*}\left[B_{t}=1\right] \geq 60 \%$ & 40.88 & 31.57 & 33.00 & 43.79 & 26.19 & 50.00 & 59.94 & 35.92 & 71.42 \\
\hline$P_{t-5}^{*}\left[B_{t}=1\right] \geq 75 \%$ & 38.87 & 31.97 & 33.00 & 41.70 & 26.84 & 46.00 & 59.94 & 35.70 & 71.42 \\
\hline$P_{t-5}^{*}\left[B_{t}=1\right] \geq 90 \%$ & 31.80 & 30.55 & 25.00 & 36.28 & 28.05 & 33.00 & 48.13 & 30.71 & 50.00 \\
\hline \multicolumn{10}{|c|}{ End Sample Bubbles Statistics } \\
\hline$P_{T-1}^{*}\left[B_{T}=1\right] \geq 60 \%$ & 54.00 & 50.09 & 100.00 & 77.38 & 42.09 & 100.00 & 75.00 & 43.52 & 100.00 \\
\hline$P_{T-1}^{*}\left[B_{T}=1\right] \geq 75 \%$ & 50.00 & 50.25 & 50.00 & 73.81 & 44.23 & 100.00 & 75.00 & 43.52 & 100.00 \\
\hline$P_{T-1}^{*}\left[B_{T}=1\right] \geq 90 \%$ & 31.00 & 46.48 & 0.00 & 61.91 & 48.85 & 100.00 & 44.00 & 49.89 & 0.00 \\
\hline$P_{T-2}^{*}\left[B_{T}=1\right] \geq 60 \%$ & 47.00 & 50.16 & 0.00 & 71.43 & 45.45 & 100.00 & 76.00 & 42.92 & 100.00 \\
\hline$P_{T-2}^{*}\left[B_{T}=1\right] \geq 75 \%$ & 42.00 & 49.60 & 0.00 & 65.48 & 47.83 & 100.00 & 76.00 & 42.92 & 100.00 \\
\hline$P_{T-2}^{*}\left[B_{T}=1\right] \geq 90 \%$ & 24.00 & 42.92 & 0.00 & 54.76 & 50.07 & 100.00 & 57.00 & 49.76 & 100.00 \\
\hline$P_{T-3}^{*}\left[B_{T}=1\right] \geq 60 \%$ & 41.00 & 49.43 & 0.00 & 61.91 & 48.85 & 100.00 & 76.00 & 42.92 & 100.00 \\
\hline$P_{T-3}^{*}\left[B_{T}=1\right] \geq 75 \%$ & 37.00 & 48.52 & 0.00 & 59.52 & 49.38 & 100.00 & 76.00 & 42.92 & 100.00 \\
\hline$P_{T-3}^{*}\left[B_{T}=1\right] \geq 90 \%$ & 24.00 & 42.92 & 0.00 & 47.62 & 50.24 & 0.00 & 57.00 & 49.76 & 100.00 \\
\hline$P_{T-4}^{*}\left[B_{T}=1\right] \geq 60 \%$ & 35.00 & 47.94 & 0.00 & 60.71 & 49.13 & 100.00 & 76.00 & 42.92 & 100.00 \\
\hline$P_{T-4}^{*}\left[B_{T}=1\right] \geq 75 \%$ & 34.00 & 47.61 & 0.00 & 59.52 & 49.38 & 100.00 & 76.00 & 42.92 & 100.00 \\
\hline$P_{T-4}^{*}\left[B_{T}=1\right] \geq 90 \%$ & 22.00 & 41.63 & 0.00 & 45.24 & 50.07 & 0.00 & 61.00 & 49.02 & 100.00 \\
\hline$P_{T-5}^{*}\left[B_{T}=1\right] \geq 60 \%$ & 31.00 & 47.94 & 0.00 & 53.57 & 49.13 & 100.00 & 77.00 & 42.92 & 100.00 \\
\hline$P_{T-5}^{*}\left[B_{T}=1\right] \geq 75 \%$ & 27.00 & 47.61 & 0.00 & 52.38 & 49.38 & 100.00 & 77.00 & 42.92 & 100.00 \\
\hline$P_{T-5}^{*}\left[B_{T}=1\right] \geq 90 \%$ & 20.00 & 41.63 & 0.00 & 45.24 & 50.07 & 0.00 & 65.00 & 49.02 & 100.00 \\
\hline \multicolumn{10}{|c|}{ All Sample Bubbles NBA Probability Distribution } \\
\hline$P_{t-1}^{*}\left[B_{t}\right]$ & 60.41 & 39.85 & 83.68 & 73.15 & 34.85 & 94.13 & 92.46 & 5.33 & 93.05 \\
\hline$P_{t-2}^{*}\left[B_{t}\right]$ & 53.54 & 41.27 & 71.82 & 66.72 & 37.90 & 92.36 & 92.96 & 5.34 & 93.77 \\
\hline$P_{t-3}^{*}\left[B_{t}\right]$ & 47.80 & 42.08 & 23.42 & 60.97 & 40.30 & 88.14 & 93.44 & 5.35 & 94.60 \\
\hline$P_{t-4}^{*}\left[B_{t}\right]$ & 42.30 & 42.10 & 13.98 & 55.45 & 41.39 & 77.98 & 93.91 & 5.33 & 95.21 \\
\hline$P_{t-5}^{*}\left[B_{t}\right]$ & 37.37 & 41.34 & 9.14 & 48.36 & 42.23 & 25.28 & 94.12 & 6.62 & 95.58 \\
\hline \multicolumn{10}{|c|}{ End Sample Bubbles NBA Probability Distribution } \\
\hline$P_{T-1}^{*}\left[B_{T}\right]$ & 63.13 & 37.99 & 84.15 & 77.27 & 31.14 & 95.07 & 91.67 & 3.46 & 92.08 \\
\hline$P_{T-2}^{*}\left[B_{T}\right]$ & 55.43 & 40.25 & 76.95 & 71.52 & 34.81 & 93.04 & 92.20 & 3.46 & 92.56 \\
\hline$P_{T-3}^{*}\left[B_{T}\right]$ & 48.49 & 42.28 & 24.33 & 63.97 & 39.08 & 88.46 & 92.72 & 3.42 & 93.21 \\
\hline$P_{T-4}^{*}\left[B_{T}\right]$ & 43.41 & 42.26 & 15.82 & 61.81 & 40.09 & 86.88 & 93.31 & 3.42 & 94.23 \\
\hline$P_{T-5}^{*}\left[B_{T}\right]$ & 37.74 & 41.74 & 6.94 & 55.59 & 42.06 & 80.13 & 93.82 & 3.39 & 95.04 \\
\hline
\end{tabular}

we conclude that the NBA mechanism performs better for longer duration bubbles. The small length settings $(\alpha=0.1$ and $\alpha=1)$ yield similar results by considering all bubbles in the sample, but there are significant differences in the case of taking just the last bubble in the sample. For the standard bubble length, $\alpha=1$, the NBA mechanism delivers a one step ahead probability that is greater than the $90 \%$ threshold for $62 \%$ of the cases of the end sample bubbles.

Equally important is how sensitive the NBA mechanism is to different bubble scales (Table 7).

It is possible to verify that the prediction power falls with smaller scale bubbles. In the smallest scale setting, $\pi=0.5$, the mechanism can predict only $1 \%$ of all the bubbles in the sample and $4 \%$ of the last bubbles. Thus, in this scenario, the mechanism is poor for detecting small bubbles. In the largest scale setting, $\pi=0.99$, the NBA yields the best results among all the simulations conducted in this section. In this case, it anticipates $83 \%$ of all bubbles in the sample, for all probability thresholds and number of ahead periods. These results are quite intuitive since the lower is the probability of collapse $(1-\pi)$, the closer the time series gets to an exponential process in 
Table 7

Monte Carlo simulation - bubble scale.

\begin{tabular}{|c|c|c|c|c|c|c|c|c|c|}
\hline \multirow{2}{*}{$\begin{array}{l}\text { Parameters } \\
\text { Statistics }\end{array}$} & \multicolumn{3}{|c|}{$\pi=0.5$} & \multicolumn{3}{|c|}{$\pi=0.85$} & \multicolumn{3}{|c|}{$\pi=0.99$} \\
\hline & $\bar{X}$ & $\Sigma X$ & $\operatorname{Med}(X)$ & $\bar{X}$ & $\Sigma X$ & $\operatorname{Med}(X)$ & $\bar{X}$ & $\Sigma X$ & $\operatorname{Med}(X)$ \\
\hline$P^{*} / T$ & 16.75 & 20.93 & 9.00 & 84.95 & 16.42 & 91.63 & 80.40 & 23.70 & 85.00 \\
\hline$\#\left(B_{1, \ldots, T}\right)$ & 4.27 & 1.62 & 4.00 & 4.98 & 1.79 & 5.00 & 1.63 & 0.74 & 1.50 \\
\hline$\# a\left(P_{t-1}^{*}\left[B_{t}\right] \geq 60 \%\right)$ & 0.16 & 0.37 & 8.00 & 3.23 & 1.31 & 3.00 & 1.25 & 0.46 & 1.00 \\
\hline$\# e\left(P_{T-1}^{*}\left[B_{T}\right] \geq 60 \%\right)$ & 0.08 & 0.27 & 0.00 & 0.77 & 0.42 & 1.00 & 1.00 & 0.00 & 1.00 \\
\hline \multicolumn{10}{|c|}{ All Sample Bubbles Statistics } \\
\hline$P_{T-1}^{*}\left[B_{T}=1\right] \geq 60 \%$ & 4.59 & 11.16 & 0.00 & 66.44 & 23.08 & 66.00 & 83.33 & 23.57 & 100.00 \\
\hline$P_{T-1}^{*}\left[B_{T}=1\right] \geq 75 \%$ & 3.04 & 9.90 & 0.00 & 62.88 & 25.05 & 64.00 & 83.33 & 23.57 & 100.00 \\
\hline$P_{T-1}^{*}\left[B_{T}=1\right] \geq 90 \%$ & 1.46 & 6.37 & 0.00 & 54.83 & 26.76 & 57.00 & 83.33 & 23.57 & 100.00 \\
\hline$P_{T-2}^{*}\left[B_{T}=1\right] \geq 60 \%$ & 2.14 & 8.51 & 0.00 & 59.95 & 24.98 & 60.00 & 83.33 & 23.57 & 100.00 \\
\hline$P_{T-2}^{*}\left[B_{T}=1\right] \geq 75 \%$ & 1.23 & 6.11 & 0.00 & 56.60 & 26.17 & 58.00 & 83.33 & 23.57 & 100.00 \\
\hline$P_{T-2}^{*}\left[B_{T}=1\right] \geq 90 \%$ & 0.45 & 3.87 & 0.00 & 49.07 & 27.68 & 50.00 & 83.33 & 23.57 & 100.00 \\
\hline$P_{T-3}^{*}\left[B_{T}=1\right] \geq 60 \%$ & 0.45 & 3.87 & 0.00 & 55.11 & 25.85 & 60.00 & 83.33 & 23.57 & 100.00 \\
\hline$P_{T-3}^{*}\left[B_{T}=1\right] \geq 75 \%$ & 0.45 & 3.87 & 0.00 & 52.24 & 25.46 & 59.00 & 83.33 & 23.57 & 100.00 \\
\hline$P_{T-3}^{*}\left[B_{T}=1\right] \geq 90 \%$ & 0.00 & 0.00 & 0.00 & 44.79 & 27.86 & 59.00 & 83.33 & 23.57 & 100.00 \\
\hline$P_{T-4}^{*}\left[B_{T}=1\right] \geq 60 \%$ & 0.45 & 3.87 & 0.00 & 50.39 & 26.19 & 50.00 & 83.33 & 23.57 & 100.00 \\
\hline$P_{T-4}^{*}\left[B_{T}=1\right] \geq 75 \%$ & 0.00 & 0.00 & 0.00 & 48.00 & 26.84 & 50.00 & 83.33 & 23.57 & 100.00 \\
\hline$P_{T-4}^{*}\left[B_{T}=1\right] \geq 90 \%$ & 0.00 & 0.00 & 0.00 & 40.86 & 28.05 & 40.00 & 83.33 & 23.57 & 100.00 \\
\hline$P_{T-5}^{*}\left[B_{T}=1\right] \geq 60 \%$ & 0.45 & 3.87 & 0.00 & 43.79 & 26.19 & 50.00 & 83.33 & 23.57 & 100.00 \\
\hline$P_{T-5}^{*}\left[B_{T}=1\right] \geq 75 \%$ & 0.00 & 0.00 & 0.00 & 41.70 & 26.84 & 46.00 & 83.33 & 23.57 & 100.00 \\
\hline$P_{T-5}^{*}\left[B_{T}=1\right] \geq 90 \%$ & 0.00 & 0.00 & 0.00 & 36.28 & 28.05 & 33.00 & 83.33 & 23.57 & 100.00 \\
\hline \multicolumn{10}{|c|}{ End Sample Bubbles Statistics } \\
\hline$P_{T-1}^{*}\left[B_{T}=1\right] \geq 60 \%$ & 8.10 & 27.48 & 0.00 & 77.38 & 42.09 & 100.00 & 100.00 & 0.00 & 100.00 \\
\hline$P_{T-1}^{*}\left[B_{T}=1\right] \geq 75 \%$ & 6.75 & 25.27 & 0.00 & 73.81 & 44.23 & 100.00 & 100.00 & 0.00 & 100.00 \\
\hline$P_{T-1}^{*}\left[B_{T}=1\right] \geq 90 \%$ & 4.05 & 19.85 & 0.00 & 61.91 & 48.85 & 100.00 & 100.00 & 0.00 & 100.00 \\
\hline$P_{T-2}^{*}\left[B_{T}=1\right] \geq 60 \%$ & 5.40 & 22.76 & 0.00 & 71.43 & 45.45 & 100.00 & 100.00 & 0.00 & 100.00 \\
\hline$P_{T-2}^{*}\left[B_{T}=1\right] \geq 75 \%$ & 4.05 & 19.85 & 0.00 & 65.48 & 47.83 & 100.00 & 100.00 & 0.00 & 100.00 \\
\hline$P_{T-2}^{*}\left[B_{T}=1\right] \geq 90 \%$ & 1.35 & 11.62 & 0.00 & 54.76 & 50.07 & 100.00 & 100.00 & 0.00 & 100.00 \\
\hline$P_{T-3}^{*}\left[B_{T}=1\right] \geq 60 \%$ & 1.35 & 11.62 & 0.00 & 61.91 & 48.85 & 100.00 & 100.00 & 0.00 & 100.00 \\
\hline$P_{T-3}^{*}\left[B_{T}=1\right] \geq 75 \%$ & 1.35 & 11.62 & 0.00 & 59.52 & 49.38 & 100.00 & 100.00 & 0.00 & 100.00 \\
\hline$P_{T-3}^{*}\left[B_{T}=1\right] \geq 90 \%$ & 0.00 & 0.00 & 0.00 & 47.62 & 50.24 & 0.00 & 100.00 & 0.00 & 100.00 \\
\hline$P_{T-4}^{*}\left[B_{T}=1\right] \geq 60 \%$ & 1.35 & 11.62 & 0.00 & 60.71 & 49.13 & 100.00 & 100.00 & 0.00 & 100.00 \\
\hline$P_{T-4}^{*}\left[B_{T}=1\right] \geq 75 \%$ & 0.00 & 0.00 & 0.00 & 59.52 & 49.38 & 100.00 & 100.00 & 0.00 & 100.00 \\
\hline$P_{T-4}^{*}\left[B_{T}=1\right] \geq 90 \%$ & 0.00 & 0.00 & 0.00 & 45.24 & 50.07 & 0.00 & 100.00 & 0.00 & 100.00 \\
\hline$P_{T-5}^{*}\left[B_{T}=1\right] \geq 60 \%$ & 1.35 & 11.62 & 0.00 & 53.57 & 49.13 & 100.00 & 100.00 & 0.00 & 100.00 \\
\hline$P_{T-5}^{*}\left[B_{T}=1\right] \geq 75 \%$ & 0.00 & 0.00 & 0.00 & 52.38 & 49.38 & 100.00 & 100.00 & 0.00 & 100.00 \\
\hline$P_{T-5}^{*}\left[B_{T}=1\right] \geq 90 \%$ & 0.00 & 0.00 & 0.00 & 45.24 & 50.07 & 0.00 & 100.00 & 0.00 & 100.00 \\
\hline \multicolumn{10}{|c|}{ All Sample Bubbles NBA Probability Distribution } \\
\hline$P_{t-1}^{*}\left[B_{t}\right]$ & 27.60 & 34.15 & 6.08 & 73.15 & 34.85 & 94.13 & 98.93 & 0.97 & 99.25 \\
\hline$P_{t-2}^{*}\left[B_{t}\right]$ & 14.50 & 28.40 & 1.34 & 66.72 & 37.90 & 92.36 & 99.01 & 0.74 & 99.19 \\
\hline$P_{t-3}^{*}\left[B_{t}\right]$ & 7.66 & 21.19 & 0.77 & 60.97 & 40.30 & 88.14 & 98.99 & 0.85 & 99.19 \\
\hline$P_{t-4}^{*}\left[B_{t}\right]$ & 3.61 & 13.47 & 0.71 & 55.45 & 41.39 & 77.98 & 99.02 & 0.76 & 99.12 \\
\hline$P_{t-5}^{*}\left[B_{t}\right]$ & 2.30 & 10.06 & 0.67 & 48.36 & 42.23 & 25.28 & 99.14 & 0.60 & 99.38 \\
\hline \multicolumn{10}{|c|}{ End Sample Bubbles NBA Probability Distribution } \\
\hline$P_{T-1}^{*}\left[B_{T}\right]$ & 29.65 & 37.44 & 4.18 & 77.27 & 31.14 & 95.07 & 98.89 & 0.61 & 99.01 \\
\hline$P_{T-2}^{*}\left[B_{T}\right]$ & 19.45 & 32.23 & 1.38 & 71.52 & 34.81 & 93.04 & 98.99 & 0.76 & 99.07 \\
\hline$P_{T-3}^{*}\left[B_{T}\right]$ & 10.68 & 23.08 & 0.88 & 63.97 & 39.08 & 88.46 & 99.09 & 0.69 & 99.32 \\
\hline$P_{T-4}^{*}\left[B_{T}\right]$ & 4.94 & 15.49 & 0.82 & 61.81 & 40.09 & 86.88 & 99.12 & 0.56 & 99.26 \\
\hline$P_{T-5}^{*}\left[B_{T}\right]$ & 2.58 & 8.55 & 0.75 & 55.59 & 42.06 & 80.13 & 99.21 & 0.59 & 99.37 \\
\hline
\end{tabular}

which collapses cease to exist. It is worth mentioning that the NBA mechanism does a perfect job in not missing a single bubble (100\% success rate) in one situation: the highest bubble scale $(\pi=0.99)$, and for up to five periods ahead in predicting the last bubble of the sample.

Table 8 reports the results for different bubble eruption frequencies.

It shows a poor performance in the case of a large number of bubble eruptions. This might seem contradictory to the learning dynamic process described above, but one should keep in mind that in Evans (1991) it is emphasized how it generates a higher number of small scale bubbles when $\delta$ is larger than $\alpha$, which is the case. As demonstrated above, the NBA mechanism can predict bubbles of only a certain scale, and therefore performs badly for this particular combination of parameters. On the contrary, by considering the case in which the number of bubble eruptions is small, $\delta<\alpha$, our procedure delivers a proper anticipation power. So the conclusion is: the NBA procedure is more responsive to few large scale bubbles than to several small scale bubbles.

The bigger the bubble, the more buzz around it in the (financial) news as for example the recent bitcoin case, the higher the fear of 
Table 8

Monte Carlo simulation - bubble restarting value.

\begin{tabular}{|c|c|c|c|c|c|c|c|c|c|}
\hline \multirow{2}{*}{$\frac{\text { Parameters }}{\text { Statistics }}$} & \multicolumn{3}{|c|}{$\delta=0.05$} & \multicolumn{3}{|l|}{$\delta=1$} & \multicolumn{3}{|l|}{$\delta=5$} \\
\hline & $\bar{X}$ & $\Sigma X$ & $\operatorname{Med}(X)$ & $\bar{X}$ & $\Sigma X$ & $\operatorname{Med}(X)$ & $\bar{X}$ & $\Sigma X$ & $\operatorname{Med}(X)$ \\
\hline$P^{*} / T$ & 61.15 & 19.51 & 65.00 & 84.95 & 16.42 & 91.63 & 80.17 & 17.61 & 87.00 \\
\hline$\#\left(B_{1, \ldots, T}\right)$ & 6.14 & 2.04 & 6.00 & 4.98 & 1.79 & 5.00 & 8.98 & 3.31 & 9.00 \\
\hline$\# a\left(P_{t-1}^{*}\left[B_{t}\right] \geq 60 \%\right)$ & 2.98 & 1.36 & 3.00 & 3.23 & 1.31 & 3.00 & 3.45 & 1.51 & 4.00 \\
\hline$\# e\left(P_{T-1}^{*}\left[B_{T}\right] \geq 60 \%\right)$ & 0.73 & 0.45 & 1.00 & 0.77 & 0.42 & 1.00 & 0.45 & 0.50 & 0.00 \\
\hline \multicolumn{10}{|c|}{ All Sample Bubbles Statistics } \\
\hline$P_{t-1}^{*}\left[B_{t}=1\right] \geq 60 \%$ & 51.01 & 22.28 & 50.00 & 66.44 & 23.08 & 66.00 & 45.81 & 27.69 & 40.00 \\
\hline$P_{t-1}^{*}\left[B_{t}=1\right] \geq 75 \%$ & 49.93 & 23.18 & 50.00 & 62.88 & 25.05 & 64.00 & 43.94 & 28.43 & 33.33 \\
\hline$P_{t-1}^{*}\left[B_{t}=1\right] \geq 90 \%$ & 41.12 & 25.81 & 37.50 & 54.83 & 26.76 & 57.00 & 32.70 & 28.26 & 25.00 \\
\hline$P_{t-2}^{*}\left[B_{t}=1\right] \geq 60 \%$ & 47.95 & 22.99 & 50.00 & 59.95 & 24.98 & 60.00 & 39.91 & 27.47 & 33.33 \\
\hline$P_{t-2}^{*}\left[B_{t}=1\right] \geq 75 \%$ & 46.27 & 24.39 & 50.00 & 56.60 & 26.17 & 58.00 & 37.75 & 27.80 & 33.33 \\
\hline$P_{t-2}^{*}\left[B_{t}=1\right] \geq 90 \%$ & 35.70 & 26.01 & 33.33 & 49.07 & 27.68 & 50.00 & 29.06 & 26.68 & 22.22 \\
\hline$P_{t-3}^{*}\left[B_{t}=1\right] \geq 60 \%$ & 44.01 & 23.42 & 42.86 & 55.11 & 25.85 & 60.00 & 36.02 & 27.99 & 30.00 \\
\hline$P_{t-3}^{*}\left[B_{t}=1\right] \geq 75 \%$ & 41.60 & 24.20 & 38.75 & 52.24 & 25.46 & 59.00 & 33.91 & 28.23 & 25.00 \\
\hline$P_{t-3}^{*}\left[B_{t}=1\right] \geq 90 \%$ & 31.53 & 24.58 & 25.00 & 44.79 & 27.86 & 59.00 & 26.72 & 26.35 & 20.00 \\
\hline$P_{t-4}^{*}\left[B_{t}=1\right] \geq 60 \%$ & 39.32 & 24.38 & 35.42 & 50.39 & 26.19 & 50.00 & 32.41 & 27.75 & 25.00 \\
\hline$P_{t-4}^{*}\left[B_{t}=1\right] \geq 75 \%$ & 36.43 & 25.16 & 33.33 & 48.00 & 26.84 & 50.00 & 30.36 & 27.46 & 20.00 \\
\hline$P_{t-4}^{*}\left[B_{t}=1\right] \geq 90 \%$ & 28.34 & 25.37 & 20.00 & 40.86 & 28.05 & 40.00 & 24.55 & 26.56 & 14.30 \\
\hline$P_{t-5}^{*}\left[B_{t}=1\right] \geq 60 \%$ & 34.80 & 24.38 & 30.95 & 43.79 & 26.19 & 50.00 & 27.73 & 27.75 & 20.00 \\
\hline$P_{t-5}^{*}\left[B_{t}=1\right] \geq 75 \%$ & 32.29 & 25.16 & 25.00 & 41.70 & 26.84 & 46.00 & 26.49 & 27.46 & 20.00 \\
\hline$P_{t-5}^{*}\left[B_{t}=1\right] \geq 90 \%$ & 24.31 & 25.37 & 16.67 & 36.28 & 28.05 & 33.00 & 20.76 & 26.56 & 11.11 \\
\hline \multicolumn{10}{|c|}{ End Sample Bubbles Statistics } \\
\hline$P_{T-1}^{*}\left[B_{T}=1\right] \geq 60 \%$ & 72.73 & 44.79 & 100.00 & 77.38 & 42.09 & 100.00 & 45.16 & 50.04 & 0.00 \\
\hline$P_{T-1}^{*}\left[B_{T}=1\right] \geq 75 \%$ & 68.18 & 46.84 & 100.00 & 73.81 & 44.23 & 100.00 & 43.01 & 49.78 & 0.00 \\
\hline$P_{T-1}^{*}\left[B_{T}=1\right] \geq 90 \%$ & 56.82 & 49.82 & 100.00 & 61.91 & 48.85 & 100.00 & 27.96 & 45.12 & 0.00 \\
\hline$P_{T-2}^{*}\left[B_{T}=1\right] \geq 60 \%$ & 65.91 & 47.67 & 100.00 & 71.43 & 45.45 & 100.00 & 36.56 & 48.42 & 0.00 \\
\hline$P_{T-2}^{*}\left[B_{T}=1\right] \geq 75 \%$ & 62.50 & 48.69 & 100.00 & 65.48 & 47.83 & 100.00 & 33.33 & 47.40 & 0.00 \\
\hline$P_{T-2}^{*}\left[B_{T}=1\right] \geq 90 \%$ & 47.73 & 50.24 & 0.00 & 54.76 & 50.07 & 100.00 & 24.73 & 43.38 & 0.00 \\
\hline$P_{T-3}^{*}\left[B_{T}=1\right] \geq 60 \%$ & 59.09 & 49.45 & 100.00 & 61.91 & 48.85 & 100.00 & 33.33 & 47.40 & 0.00 \\
\hline$P_{T-3}^{*}\left[B_{T}=1\right] \geq 75 \%$ & 56.82 & 49.82 & 100.00 & 59.52 & 49.38 & 100.00 & 32.26 & 47.00 & 0.00 \\
\hline$P_{T-3}^{*}\left[B_{T}=1\right] \geq 90 \%$ & 40.91 & 49.45 & 0.00 & 47.62 & 50.24 & 0.00 & 19.36 & 39.72 & 0.00 \\
\hline$P_{T-4}^{*}\left[B_{T}=1\right] \geq 60 \%$ & 52.27 & 50.24 & 100.00 & 60.71 & 49.13 & 100.00 & 30.11 & 46.12 & 0.00 \\
\hline$P_{T-4}^{*}\left[B_{T}=1\right] \geq 75 \%$ & 50.00 & 50.29 & 50.00 & 59.52 & 49.38 & 100.00 & 27.96 & 45.12 & 0.00 \\
\hline$P_{T-4}^{*}\left[B_{T}=1\right] \geq 90 \%$ & 34.09 & 47.67 & 0.00 & 45.24 & 50.07 & 0.00 & 17.20 & 37.95 & 0.00 \\
\hline$P_{T-5}^{*}\left[B_{T}=1\right] \geq 60 \%$ & 44.32 & 50.24 & 0.00 & 53.57 & 49.13 & 100.00 & 26.88 & 46.12 & 0.00 \\
\hline$P_{T-5}^{*}\left[B_{T}=1\right] \geq 75 \%$ & 43.18 & 50.29 & 0.00 & 52.38 & 49.38 & 100.00 & 23.66 & 45.12 & 0.00 \\
\hline$P_{T-5}^{*}\left[B_{T}=1\right] \geq 90 \%$ & 30.68 & 47.67 & 0.00 & 45.24 & 50.07 & 0.00 & 15.05 & 37.95 & 0.00 \\
\hline \multicolumn{10}{|c|}{ All Sample Bubbles NBA Probability Distribution } \\
\hline$P_{t-1}^{*}\left[B_{t}\right]$ & 68.04 & 39.26 & 92.00 & 73.15 & 34.85 & 94.13 & 43.98 & 40.49 & 18.09 \\
\hline$P_{t-2}^{*}\left[B_{t}\right]$ & 63.58 & 40.69 & 88.00 & 66.72 & 37.90 & 92.36 & 37.78 & 39.97 & 11.95 \\
\hline$P_{t-3}^{*}\left[B_{t}\right]$ & 57.76 & 41.95 & 82.00 & 60.97 & 40.30 & 88.14 & 32.90 & 39.21 & 8.00 \\
\hline$P_{t-4}^{*}\left[B_{t}\right]$ & 50.79 & 42.69 & 52.00 & 55.45 & 41.39 & 77.98 & 28.58 & 38.03 & 6.08 \\
\hline$P_{t-5}^{*}\left[B_{t}\right]$ & 44.81 & 43.22 & 16.00 & 48.36 & 42.23 & 25.28 & 24.51 & 36.38 & 4.17 \\
\hline \multicolumn{10}{|c|}{ End Sample Bubbles NBA Probability Distribution } \\
\hline$P_{T-1}^{*}\left[B_{T}\right]$ & 69.56 & 36.88 & 92.48 & 77.27 & 31.14 & 95.07 & 46.60 & 41.23 & 18.85 \\
\hline$P_{T-2}^{*}\left[B_{T}\right]$ & 64.87 & 39.34 & 88.48 & 71.52 & 34.81 & 93.04 & 38.41 & 40.97 & 10.15 \\
\hline$P_{T-3}^{*}\left[B_{T}\right]$ & 57.89 & 41.56 & 83.18 & 63.97 & 39.08 & 88.46 & 35.55 & 41.03 & 7.77 \\
\hline$P_{T-4}^{*}\left[B_{T}\right]$ & 51.56 & 42.50 & 74.82 & 61.81 & 40.09 & 86.88 & 31.48 & 40.10 & 6.63 \\
\hline$P_{T-5}^{*}\left[B_{T}\right]$ & 44.53 & 42.98 & 17.23 & 55.59 & 42.06 & 80.13 & 27.94 & 38.92 & 4.00 \\
\hline
\end{tabular}

missing out large returns and the higher the hysteria around the asset. This constitutes a pronounced self-fulfilling loop that lasts in which the price increases following what happened in the past period. The dynamic nature of our probit model where exuberance and abnormality comes together over time makes it harder to detect a bubble that burst right after it started.

\section{Application to real data}

In this Section we apply the NBA mechanism to approximately 35 years (1990-2019) of weekly and monthly Apple and NASDAQ Composite data. Both cover roughly the sample sizes of the Monte Carlo experiments (about 400 and 2000 data points) and have time horizons that investors often consider in their portfolio decisions (weekly and monthly). The Monte Carlo simulations provided very encouraging results in terms of the ability for our procedure to anticipate exuberance behavior, so we now use real financial data to 


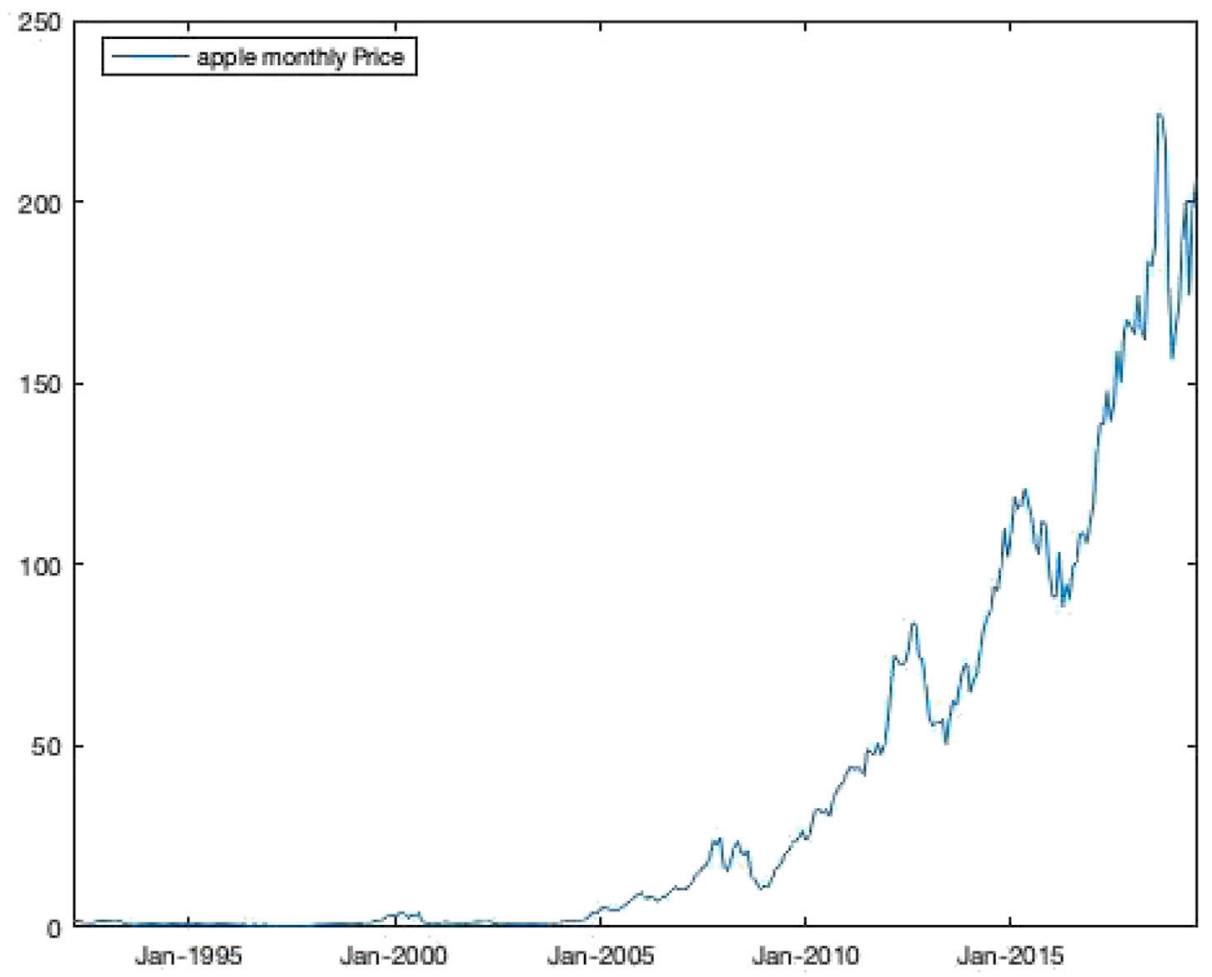

Fig. 7. Apple stock price.

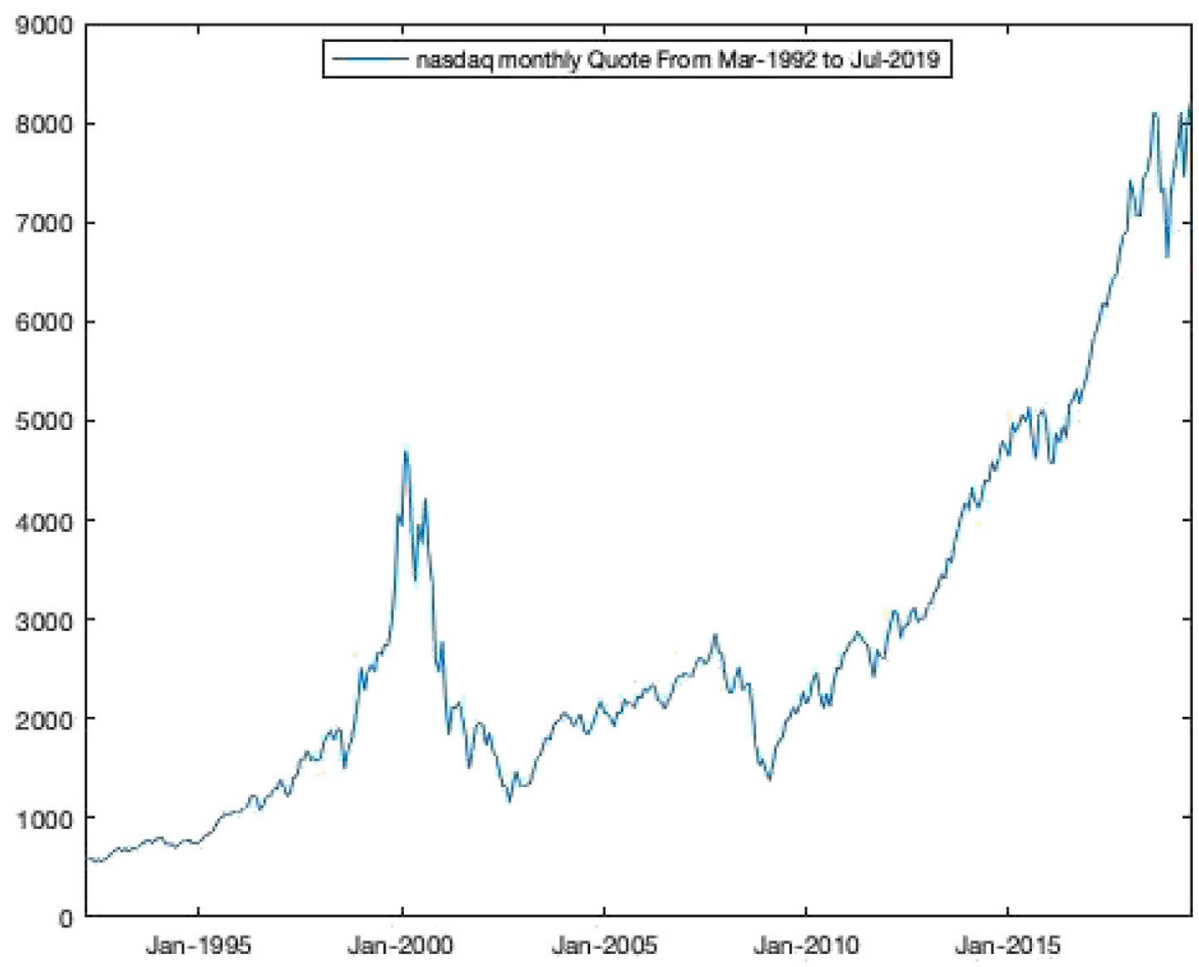

Fig. 8. Nasdaq composite index. 
check whether it could have anticipated the dotcom bubble. As before, our method is to be considered reliable if it can estimate a very significant one step ahead probability toward the bubble peak.

The observed Apple Stock Price and NASDAQ Composite Index are in Figs. 7 and 8, respectively. After launching its initial public offering on December 12, 1980, Apple's first two for one stock split occurred on June 16, 1987. The initial data consumption of the procedure implies starting in 1990. Although we estimate other periods of price exuberance, we focus at the Tech dotcom bubble because it is the most obvious one for which the CAPM can accurately derive the abnormal returns included in the proposed model.

The exuberance episode of interest takes place around the year 2000. In fact, the technological bubble resembles some of the properties of the simulated data in which the NBA mechanism performs best: few large scale bubbles. One can easily understand the exacerbated acceleration each security takes in the quoted period. If the investor expects the price to go higher, he will want to take a long position in the Apple stock as soon as possible and close that position just before the price starts to collapse and return to its fair value, that is, he surfs the bubble as explained in Brunnermeier and Abreu (2003).

By applying our methodology to the stock data, we observe similar results to those using simulated data. Around the year 2000 there is a sharp increase in all estimated NBA's parameters with the respective statistical significance, emphasizing the idea of having a robust estimation method that supports the calculation of the one step ahead probability. Again, it is important to stress that the statistical significance of the abnormal return in the model is a revealing indicator of a proper estimation using both fundamentals and subjective rate of return. During year 1999, the financial market finds evidence of Apple's price explosion (in our procedure, based upon the BSADF statistic). But an agent doesn't know yet if it is due to fundamentals or exuberance. Then, as year 1999 reaches its end, an agent observes a price considered more apart from his/her subjective expectations and therefore, valuing more the correspondent abnormal return, suspects that the chance of bursting the bubble is increasing According to the Adaptive Learning theory, agents always include the most recent data available at the statistical "model" they have in their heads and so, a rise in the statistical significance of the parameters of the "model" provides additional trust in the procedure's outcome and the chosen investment strategy.

The validated (and not validated) one step ahead probability, illustrated in Figs. 9 and 10, confirms that the NBA mechanism was able to anticipate the technological bubble. The probability is $85 \%$ three months before the bubble peak and more than $90 \%$ one month before the bubble peak. More precisely, the probability equals $66 \%$ seven months prior to the peak, rising to $85 \%$ three months before and ending at a $94 \%$ level the month prior to the peak. In other words, our methodology was anticipating the collapse before it happened (ex-ante prediction).

The results for weekly and monthly data are almost identical. In October 1999 the probabilities are less than $80 \%$ (the first two weeks are about $1 \%$ ) and in November they fluctuate around $78 \%-81 \%$. Thereafter, the probabilities hover around $80 \%-90 \%$ before the bubble peak.

These results have important implications in the decision theory for investors. Looking at the specific case of the tech bubble, if an

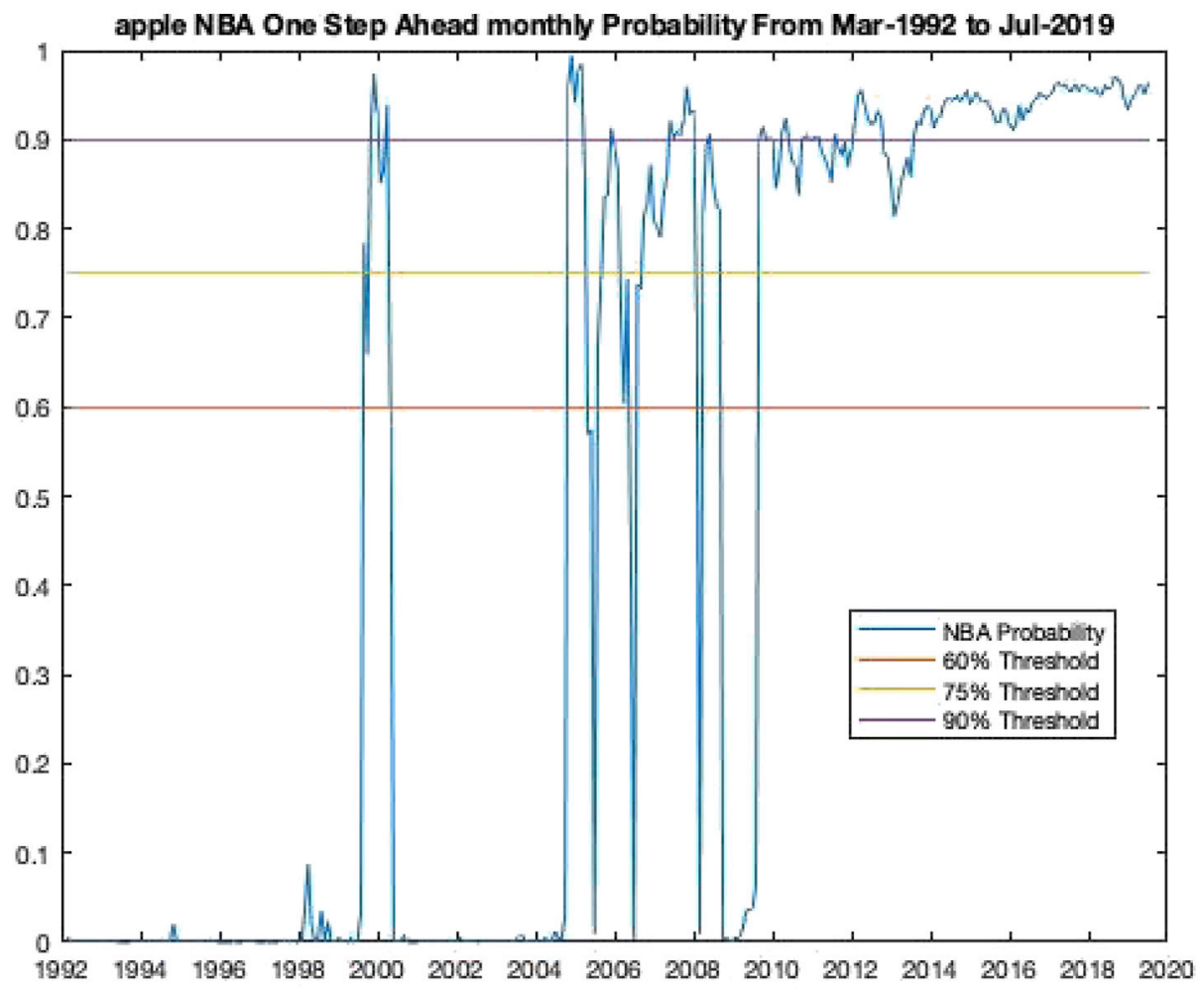

Fig. 9. Bubble probability (stock data). 
apple NBA One Step Ahead monthly Validated Probability From Mar-1992 to Jul-2019

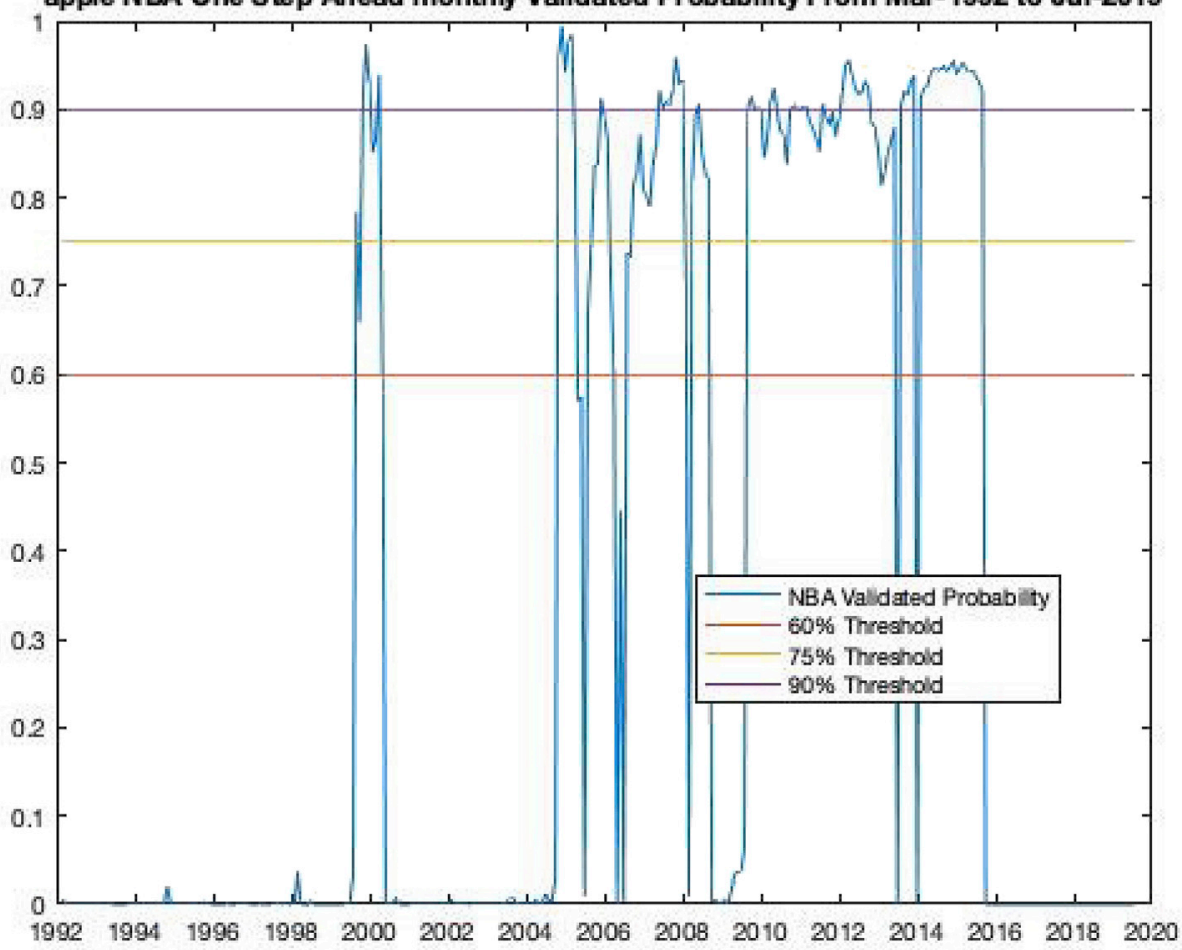

Fig. 10. Bubble validated probability (stock data).

investor had made his/her portfolio adjustments according to the NBA procedure, he/she could have made a non-negligible profit. In practice, by running our method, if the one step ahead probability exceeds a very high threshold, for example $80 \%$, he/she has a strong incentive to increase the relative weight of the Apple stock in the portfolio since a higher rate of return is expected for the following month. The investor repeats this strategy until he/she obtains a clear signal that exuberance has stopped. On the other hand, from a regulator's perspective, if it is to be assumed that investors are going to adopt this type of strategy, there is the chance of a temporary suspension in the trading of stocks to avoid a market crash.

\section{Conclusion}

Far more challenging than explaining ex-post events is proposing an accurate anticipative ex-ante method that can be used to estimate an early warning system for predicting systemic crises. The NBA is a statistical mechanism capable of anticipating price exuberance by estimating a significant probability of such rare events occurring at least one step ahead of the bubble peak, and whose main novelty is the incorporation of fundamentals explained by asset pricing theory into the standard approach of testing for the presence of bubbles in time series. Another methodological innovation is the introduction of the social feedback loop of Shiller (2000) through the use of a dynamic model specification.

The Monte Carlo simulations showed that the fundamentals are essential to a better ex-ante prediction, representing an improvement of $900 \%$ when compared to not adding the estimated abnormal returns into the model. The mechanism presents a high anticipation capability when bubbles are longer lasting and larger scale, especially when predicting the last bubble of the sample. In some cases, the NBA mechanism was able to predict $100 \%$ of the last bubbles up to five periods before the peak. The method was applied to the Apple and NASDAQ Composite weekly and monthly data from 1990 to 2019 and its usefulness with real data was confirmed by providing probabilities greater than $85 \%$ and $90 \%$ three months and one month, respectively, before the technological bubble peak of 2000 .

The new procedure can be important for both investors and market regulators due to its ex-ante nature. It allows both of these agents to anticipate exuberance one step ahead and act according to their own objectives. That is, the results show that the NBA mechanism provides an enormous advantage for investors interested in optimizing the portfolio and performing a very profitable "bubble surfing" strategy, likely to be adopted in this type of event, and for market regulators whose responsibility is to maintain market efficiency.

There are several forms of extending the application of the newly proposed mechanism, namely the estimation of the components from which one draws the probability of exuberance: the abnormal returns, and the non-stationarity test statistic. We believe that the CAPM equilibrium model is a good and well-established specification for obtaining the abnormal returns. More recent, less parsimonious, and less tractable models include, among others, time-varying risk premium specifications (see, for example, Gagliardini, Ossola, \& Scaillet, 2016). Another important aspect is how the subjective rate of return is estimated, that is, the choice of the learning rule. For generalization matters, the suggested learning rule was essentially a recursively updated mean rate of return. Definitely, one can 
consider far more complicated learning rules. Finally, it is also possible to change the test statistic used to capture price acceleration (see, for example, Harvey, Leybourne, \& Zu, 2019). Nonetheless, one should consider both effectiveness and efficiency of the choices. Otherwise the NBA's power can be affected because the identification of potential exuberance starts with an unusual price acceleration and the chosen statistic must identify the event with the minimum data consumption.

\section{References}

Alessi, L., \& Detken, C. (2011). Quasi real time early warning indicators for costly asset price boom/bust cycles: A role for global liquidity. European Journal of Political Economy, 27(3), 520-533.

Astill, S., Harvey, D. I., Leybourne, \& Taylor, A. M. R. (2017). Tests for an end-of-sample bubble in financial time series. Econometric Reviews, 36 , 651-666.

Barberis, N. C., Greenwood, R., Jin, L., \& Shleifer, A. (2018). Extrapolation and bubbles. Journal of Financial Economics, 129, $203-227$.

Beckers, B. (2015). The real-time predictive content of asset price bubbles for macro forecasts. Berlin: DIW. Discussion Paper 1496.

Blanchard, O. (1982). Bubbles, rational expectations and financial markets. In Crises in the Economic and financial structure, Paul Wachtel (pp. 295-316). Lexington, MA: D.C. Heathand Company.

Blanchard, O., \& Watson, M. W. (1979). Speculative bubbles, crashes and rational expectations. Economics Letters, 3(4), 387-389.

Branch, W. A., \& Evans, G. W. (2011). Learning about risk and return: A simple model of bubbles and crashes. American Economic Journal: Macroeconomics, 3(3), $159-191$.

Bray, M. (1982). Learning, estimation, and the stability of rational expectations. Journal of Economic Theory, 26(2), 318-339.

Breitung, J. (2014). Econometric tests for speculative bubbles. Bonn Journal of Economics, 3(1), 113-127.

Breitung, J., \& Kruse, R. (2013). When bubbles burst: Econometric tests based on structural breaks. Statistical Papers, 54(4), 911-930.

Brunnermeier, M., \& Abreu, D. (2003). Bubbles and crashes. Econometrica, 71(1), 173-204.

Brunnermeier, M., \& Schnabel, I. (2015). Bubbles and Central banks: Historical perspectives. In CEPR discussion papers 10528. C.E.P.R. Discussion Papers.

Chong, J., \& Hurn, A. S. (2015). Testing for speculative bubbles: Revisiting the rolling window. Working paper. School of economics and finance. Queensland University of Technology.

Cochrane, J. (2005). Asset pricing. Princeton University Press.

Cuñado, J., Gil-Alana, L., \& de Gracia, F. P. (2005). A test for rational bubbles in the NASDAQ stock index: A fractionally integrated approach. Journal of Banking \& Finance, 29(10), 2633-2654.

Diba, B. T., \& Grossman, H. I. (1988a). Explosive rational bubbles in stock prices? The American Economic Review, 78(3), 520-530.

Diba, B. T., \& Grossman, H. I. (1988b). The theory of rational bubbles in stock prices. Economic Journal, 98, 746-754.

Evans, G. W. (1991). Pitfalls in testing for explosive bubbles in asset prices. The American Economic Review, 81(4), 922-930.

Evans, G. W., \& Honkapohja, S. (2001). Learning and expectations in macroeconomics. Princeton University Press.

Fama, E. F. (1970). American finance association efficient capital markets: A review of theory and empirical work. The Journal of Finance, $25(2), 382-417$.

Flood, R. P., \& Hodrick, R. J. (1990). On testing for speculative bubbles. The Journal of Economic Perspectives, 4(2), 85-101.

Frankel, J. A., \& Rose, A. K. (1996). Currency crashes in emerging markets: An empirical treatment. Journal of International Economics, 41(3), $351-366$.

Franses, P. H. (2016). A simple test for a bubble based on growth and acceleration. Computational Statistics \& Data Analysis, 100, $160-169$.

Gagliardini, P., Ossola, E., \& Scaillet, O. (2016). Time-varying risk premium in large cross-sectional equity data sets. Econometrica, 84(3), 985-1046.

Greenwood, R., Shleifer, A., \& You, Y. (2019). Bubbles for Fama. Journal of Financial Economics, 131(1), $20-43$.

Gurkaynak, R. S. (2008). Econometric tests of asset price bubbles: Taking stock. Journal of Economic Surveys, 22(1), 166-186.

Hall, S. G., Sola, M., \& Psaradakis, Z. (1999). Detecting periodically collapsing bubbles: A Markov switching unit root test. Journal of Applied Econometrics, 154(2), $143-154$.

Hamilton, J. (1986). On testing self-fullfiling speculative price bubbles. International Economic Review, 27(3), 545-552.

Harvey, D. I., Leybourne, S. J., \& Sollis, R. (2015). Recursive right-tailed unit root tests for an explosive asset price bubble. Journal of Financial Econometrics, 13(1), $166-187$.

Harvey, D. I., Leybourne, S. J., \& Sollis, R. (2017). Improving the accuracy of asset price bubble start and end date estimators. Journal of Empirical Finance, 40, 121-138.

Harvey, D. I., Leybourne, S. J., Sollis, R., \& Taylor, A. M. R. (2016). Tests for explosive financial bubbles in the presence of non-stationary volatility. Journal of Empirical Finance, 38, 548-574.

Harvey, D. I., Leybourne, S. J., \& Whitehouse, E. (2019). Date-stamping multiple bubble regimes. Working Paper available at: https://sites.google.com/site/ ejwhitehouse1/research.

Harvey, D. I., Leybourne, S. J., \& Zu, Y. (2019). Sign-based unit root tests for explosive financial bubbles in the presence of deterministically time-varying volatility. Forthcoming at econometric theory.

Homm, U., \& Breitung, J. (2012). Testing for speculative bubbles in stock markets a comparison of alternative methods. Journal of Financial Econometrics, 10(1), $198-231$.

Horie, T., \& Yamamoto, Y. (2016). Testing for speculative bubbles in large-dimensional financial panel data sets. Graduate School of Economics, Hitotsubashi University. Discussion Paper Series No. 2016-04.

Jang, J., \& Kang, J. (2019). Probability of price crashes, rational speculative bubbles, and the cross-section of stock returns. Journal of Financial Economics, 132, $222-247$.

de Jong, R. M., \& Woutersen, T. (2011). Dynamic time series binary choice. Econometric Theory, 27(4), 673-702.

Kaminsky, G. L., \& Reinhart, C. M. (1999). The twin crises: The causes of banking and balance-of-payments problems. The American Economic Review, 89(3), 473-500.

Kindleberger, C. P., \& Aliber, R. Z. (2005). Manias, panics, and crashes. A history of financial crises (5th ed.). New Jersey: John Wiley \& Sons, Inc.

Lee, J. H., \& Phillips, P. C. B. (2016). Asset pricing with financial bubble risk. Journal of Empirical Finance, 38, 590-622.

Lucas, R. E. (1978). Asset prices in an exchange economy. Econometrica, 46(6), 1429-1445.

Malkiel, B. (2010). Bubbles in asset prices. CEPS Working. Paper No. 200.

Markowitz, H. (1952). Portfolio selection. The Journal of Finance, 7(1), 77-91.

Miao, J. (2014). Introduction to economic theory of bubbles. Journal of Mathematical Economics, 53, $130-136$.

Miao, J., Wang, P., \& Xu, Z. (2015). A Bayesian dynamic stochastic general equilibrium model of stock market bubbles and business cycles. Quantitative Economics, 6(3), 599-635.

Newey, K. (1987). A specification test for speculative bubbles. Quarterly Journal of Economics, 102(3), 553-580.

Nyberg, H. (2010). Dynamic probit models and financial variables in recession forecasting. Journal of Forecasting, 230, $215-230$.

Pavlidis, E. G., Paya, I., \& Peel, D. A. (2012). A new test for rational speculative bubbles using forward exchange rates: The case of the interwar German hyperinflation. Lancaster: The Department of Economics. Working Paper 51 7/09/2012.

Phillips, P. C. B., \& Shi, S. (2018). Financial bubble implosion and reverse regression. Econometric Theory, 34(4), 705-753.

Phillips, P. C. B., Shi, S., \& Yu, J. (2015a). Testing for multiple bubbles: Historical episodes of exuberance and collapse in the S\&P 500. International Economic Review, 56(4), 1043-1078.

Phillips, P. C. B., Shi, S., \& Yu, J. (2015b). Testing for multiple bubbles: Limit theory of real time detectors. International Economic Review, 56(4), $1079-1134$.

Phillips, P. C. B., Wu, Y., \& Yu, J. (2011). Explosive behavior in the 1990s Nasdaq: When did exuberance escalate asset values? International Economic Review, 52(1), $201-226$.

Scherbina, A. (2013). Asset price bubbles: A selective survey. IMF Working Paper WP/13/45. 
Sharpe, W. (1963). A simplified model for portfolio analysis. Management Science, 9(2), 227-293.

Sharpe, W. (1964). Capital asset prices: A theory of market equilibrium under conditions of risk. The Journal of Finance, 19(3), 425-442.

Shiller, R. (1981). Do stock prices move too much to be justified by subsequent changes in dividends? The American Economic Review, 71(3), $421-436$.

Shiller, R. (2000). Irrational exuberance (1st ed.). Pricenton University Press.

Shi, S., \& Song, Y. (2016). Identifying speculative bubbles using an infinite hidden Markov model. Journal of Financial Econometrics, 14(1), 159-184.

Young, C. P. (2011). Recursive estimation and time-series analysis. Berlin Heidelberg: Springer. 